\title{
Electrospun nanofibers as reinforcement for composite laminates materials - A Review
}

\author{
R. Palazzettia ${ }^{\mathrm{a}, *}$, A. Zucchelli ${ }^{\mathrm{b}}$ \\ ${ }^{a}$ University of Strathclyde, DMEM department, 75 Montrose Street, G1 1 XJ Glasgow, \\ $U K$ \\ ${ }^{b}$ University of Bologna, Department of Industrial Engineering, viale del Risorgimento 2, \\ 40136 Bologna, Italy
}

\begin{abstract}
In the last few decades nanofibers have been developed and introduced in a vast number of industrial and research applications. One of their most effective use is as interleaved reinforcement for composite laminate materials against delamination. Nanofibrous mats have the ideal morphology to be embedded between two plies of a laminate, and a vast and deep research has been carried out investigating their effect on the global behaviour of a composite laminate.

This review is the first of its kind to date which presents a detailed state-ofthe-art on the effect of nanofibrous interleaves into composite laminates with focus on the mechanical performances and behaviours of nanomodified materials. A detailed description of the working mechanisms of the nanointerleave under different load cases is presented, and a comparative analysis between papers in literature will provide readers with a powerful tool to understand and use nanofibers for reinforcing purposes.
\end{abstract}

Keywords: Nanofibers, Composite Materials, Electrospinning, Delamination, Mechanical tests, Experimental Mechanics

\footnotetext{
*Principal corresponding author

Email addresses: roberto.palazzetti@strath.ac.uk (R. Palazzetti), a.zucchelli@unibo.it (A. Zucchelli)
} 


\section{Acronyms}

\begin{tabular}{|c|c|}
\hline $3 \mathrm{~PB}$ & 3 Points Bending \\
\hline AA & Acetic Acid \\
\hline $\mathrm{AC}$ & Acetone \\
\hline $\mathrm{BuAc}$ & Butyl Acetate \\
\hline CAI & Compression After Impact \\
\hline CFRP & Carbon Fibers Reinforced Plastic \\
\hline CLF & Chloroform \\
\hline $\mathrm{CNT} / \mathrm{CNF}$ & Carbon NanoTubes/NanoFibers \\
\hline coPES & Copolyethersulfones \\
\hline DCB & Double Cantilever Beam \\
\hline DCPD & Dicyclopentadiene \\
\hline DFM & Dimethylformamide \\
\hline DMAC & Dimethylacetamide \\
\hline DMSO & Dimethyl sulfoxide \\
\hline ENF & End Notched Flexure \\
\hline ETL & Ethanol \\
\hline FA & Formic Acid \\
\hline $\mathrm{G}_{\mathrm{I}, \mathrm{C}} / \mathrm{G}_{\mathrm{I}, \mathrm{R}}$ & Mode I Critical/Propagation energy release rate \\
\hline $\mathrm{G}_{\mathrm{II}, \mathrm{C}} / \mathrm{G}_{\mathrm{II}, \mathrm{R}}$ & Mode II Critical/Propagation energy release rate \\
\hline GFRP & Glass Fibers Reinforced Plastic \\
\hline $\mathrm{HLu}$ & Hand Lay-up \\
\hline HMW & High Molecular Weight \\
\hline IFT & Impact Fracture Toughness \\
\hline ILSS & Interlaminar Shear Stress \\
\hline $\mathrm{K}_{\mathrm{I}} / \mathrm{K}_{\mathrm{II}}$ & Mode I/II fracture toughness \\
\hline $\mathrm{LiBr}$ & Lithium Bromide \\
\hline LMW & Low Molecular Weight \\
\hline LVI & Low Velocity Impact \\
\hline MDI-TAD & $4,4^{\prime}$-(4,4"-diphenylmethylene)-bis-(1,2,4-triazoline- 3,5 - dione $)$ \\
\hline MEK & Butanone \\
\hline MWCNT & Multi-Walled Carbon NanoTubes \\
\hline NA & Not Available \\
\hline $\mathrm{P}($ St-co-GMA $)$ & Epoxy compatible copolimer \\
\hline $\mathrm{PA} / \mathrm{PAI}$ & Polyamide/Polyamide-imide \\
\hline PAN & Polyacrylonitrile \\
\hline PCL & Polycaprolactone \\
\hline PEK-C & Polyetherketone \\
\hline PES & Polyethersulfone \\
\hline PGME & Propylene Glycol Monomethyl Ether \\
\hline PP - PPS & Polypropylene - Polyphenylene sulfide \\
\hline $\mathrm{PrP}$ & Prepreg \\
\hline PSF & Polysulfone \\
\hline PVA - PVB & Polyvinyl Alcohol - Polyvinyl Butyral \\
\hline PVDF & Polyvinylidene fluoride \\
\hline PW & Plain Wave \\
\hline SBS & Styrene Butadiene Styrene \\
\hline SBSh & Short Beam Shear \\
\hline SEM & Scanning Electron Microscope \\
\hline TEGO & Thermally exfoliated graphene oxide \\
\hline TEOS & Tetra Ethyl Orthosilicate \\
\hline TFE & Trifluethanol \\
\hline THF & Tetrahydrofuran \\
\hline TPU & Thermoplastic polyurethane \\
\hline TW & Tow \\
\hline UD & Unidirectional \\
\hline VARTM & Vacuum Assisted Resin Transfer Moulding \\
\hline VE & Vinylester \\
\hline
\end{tabular}




\section{Introduction}

The aim of this review is to collect the research results produced on the topic of composite laminates reinforced with polymeric electrospun nanofibers, and to present a critical and comparative summary of the most significant findings, with focus on mechanical response and behaviour of the nanomodified materials.

A laminate structures is formed by stacking anisotropic plies one on top of each other, and external excessive stresses or strains may cause a damage to start (initiate) between two laminae, and then to propagate following several failure modes. Due to the anisotropic and heterogeneous nature of the composite materials, a large number of failure modes can be detected [1], with the three main ones being: $(i)$ intra-ply cracking, $(i i)$ interlaminar matrix delamination, and (iii) fiber failure. Other types of damage simply alter the load levels at which these three occur. Amongst the three principal damage modes mentioned above, the interlaminar matrix delamination is of major importance. Delamination is a subcritical failure mode whose effect may be stiffness loss, local stress concentration, and local instability causing its further growth and eventually failure of the manufactured. Delamination is the most prevalent failure mode for composites [2], and can be caused by many factors, as shown in Figure 1.

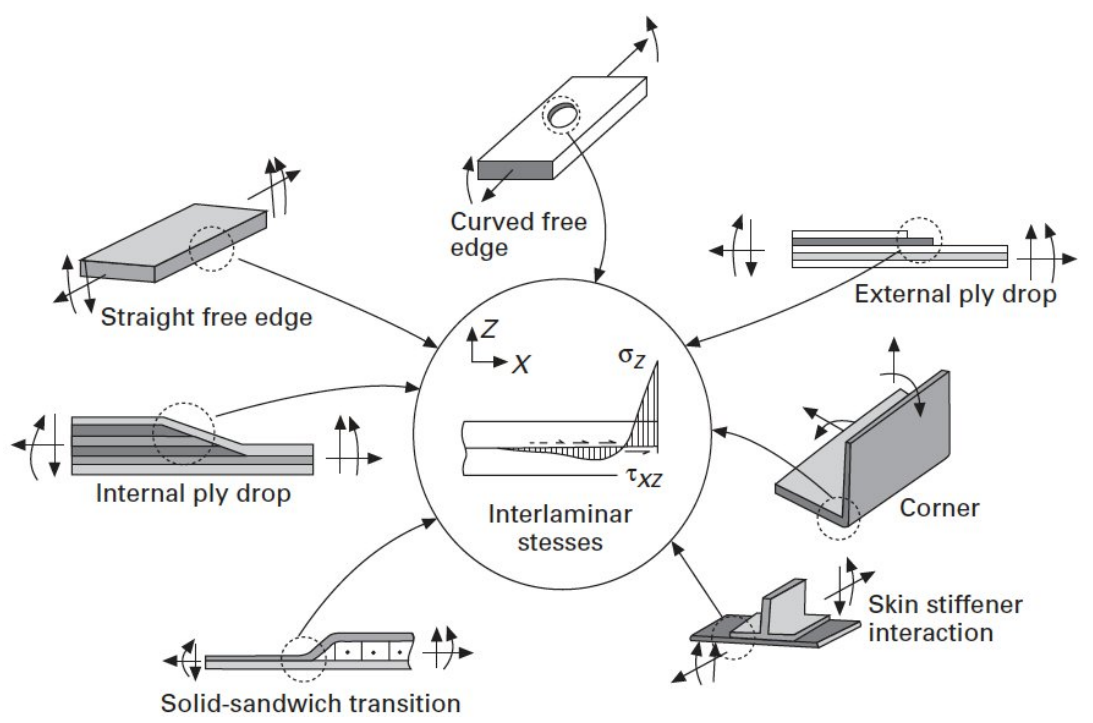

Figure 1: Causes of delamination [3]. 
Over the years many techniques have been developed to investigate and mitigate delamination, which is particularly dangerous because it appears and grows under the surface: a laminate can loose up to $60 \%$ of its compressive residual strength and stiffness and still remains visibly unchanged [4]. Among the range of solutions developed over the years targeting to solve or mitigate the delamination problem, interleaving polymeric nanofibers in interlaminar regions has proven to be one of the most effective thanks to their tiny diameter (as small as tens of nanometres), small pores (ranging from tens of nanometers to tens of micrometers) and high volumetric porosity. Nanofibers are produced by electrospinning, which first patent dates back in 1902 [5, 6], and found successful application in numerous fields, such as nanocatalysis, tissue engineering scaffolds, protective clothing, filtration, biomedical, pharmaceutical, optical electronics, healthcare, biotechnology, defence and security, environmental engineering [7-10].

In 1999, Professors Y.A. Dzenis and D.H. Reneker interleaved sheets of polymeric nanofibers between two consecutive layers of a composite laminate to improve its mechanical performances [11]. Their idea worked and the new three-phase composite material exhibited improved performances compared to the pristine configuration, and a new application for nanofibers had just been introduced.

A research on Scopus (www . scopus.com) using "Nanofibers" and "Laminate" as keywords in titles, abstract and keywords for articles, reviews and articles in press, in the areas of Material Science and Engineering, output 159 documents starting from 2002, as shown in Figure 2. Taking into account also conference papers and reviews, books and book chapters, the total number of documents rises to 298 .

In the last few decades, the research community showed great interest on the potential of nanofibers as reinforcement for laminates, and three reviews have been already published on this topic [12-14]. The first one presents the mechanical improvements of interleaving a polymeric structure (either particles, films or nanofibers) between composite laminae, while the other two focus on the range of possible applications and the actual benefits of nanomodifying laminates with nanofibers.

The intent of the present review is to analyse the state-of-the art on composite laminates interleaved with electrospun nanofibers, focusing on macroscopic mechanical performances. For the first time, the state-of-the art is depicted by direct comparison of mechanical test results between pristine and nanomodified laminates. Results from literature are presented in charts which 


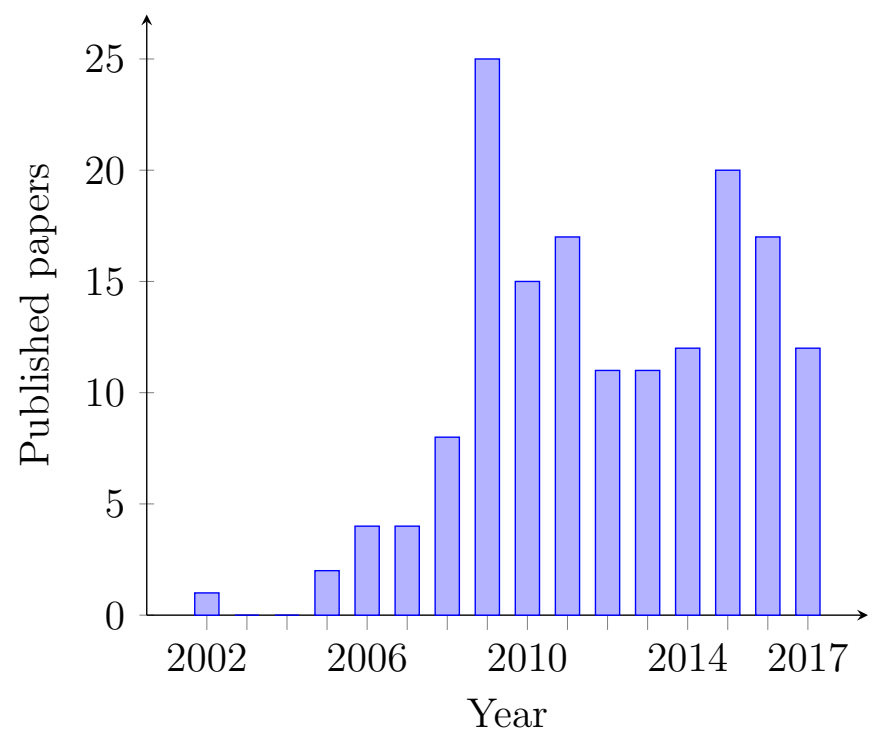

Figure 2: Published papers found using "Nanofibers" and "Laminates" keywords. Source: Scopus, August 30, 2017

relate the responses of nanomodified laminates with those of control samples, to provide the readers and the users with a clear view of the effect of the nanomodification. The same charts can also be a useful tool to select materials for practical applications.

Section $\S 2$ after a brief introduction of the electrospinning process, lists all the polymers that have been used to date for producing nanofibers for structural and reinforcing purposes; Section $\S 3$ presents a detailed analysis of the behaviour of the nanomodified composites classified according to 7 different mechanical tests: $(i)$ Mode I and (ii) Mode II fracture mechanics, (iii) Tension, (iv) Bending, ( $v$ ) Impact, (vi) Compression after impact, and (vii) Vibration. Each load case is individually presented: experimental results, working mechanism of the nanofibers, and any relevant information from the papers present in literature have been reported.

A dedicated section has been left to present the results of a recent and very effective nanoreinforce: nanofibers doped with CNT. Despite the topic may seem slightly out of the scope of this review, the strong effect that nano carbon-based materials have on the composites they are interleaved in, could not have been left out, and deserved a mention.

The general trend shows that nanofibers bring significant benefits to the 
properties of the laminate they are interleaved in; those few documents that report negative results have been collected and presented in Section $\S 4$, aiming to identify the causes and the operations that should be avoided when working with nanofibers. Section $\S 5$ identifies the research holes that still need to be filled, and presents the future perspectives of the use of nanofibers in composites; conclusions are drawn in Section $\S 6$.

\section{Electrospinning}

The electrospinning process makes use of five main components to produce polymeric nanofibers: ( $i$ ) a high voltage power supply, (ii) a feeding system that brings the polymeric solution from (iii) a reservoir to $(i v)$ a dispensing unit (a needle- or a needleless-system $[15,16]$ ), and $(v)$ a grounded collecting plate. The high voltage applied between the collector and the polymeric solution charges and accelerates this latter, which whips travelling between the capillary tip and the collector. The unstable motion aids the evaporation of the solvent(s) and stretches the polymer, which is deposited in the form of nanofibers.

The electrical field can be tuned with devices such as deflectors, electrostatic lenses, or shaped collectors. Figure 3 shows a detailed electrospinning apparatus scheme.

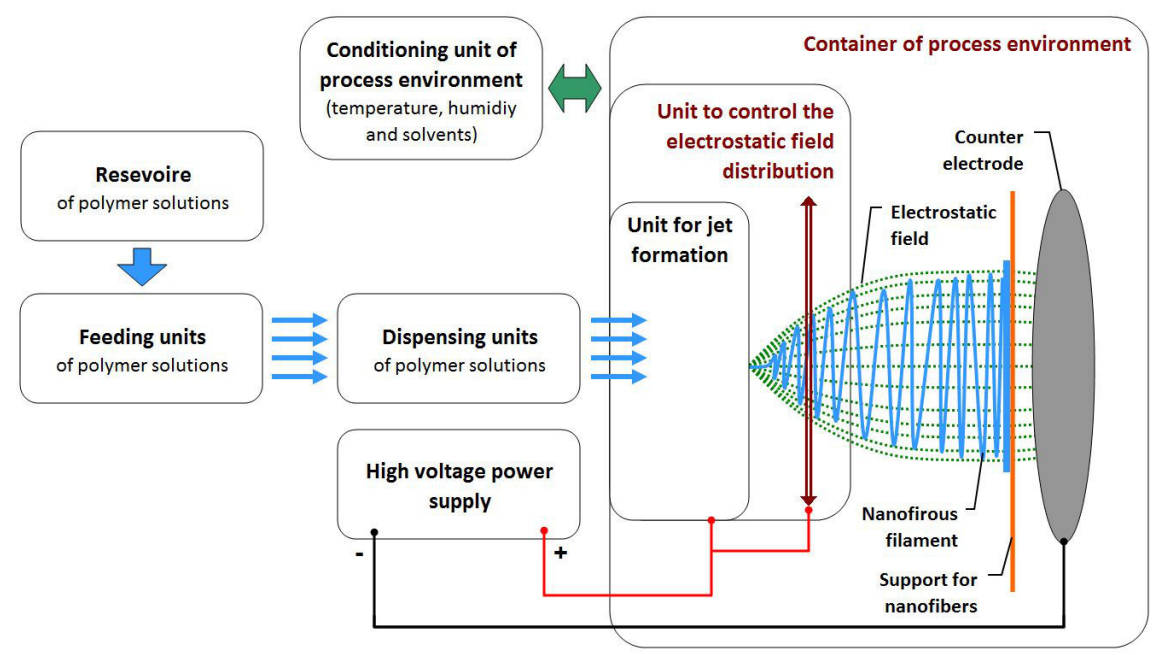

Figure 3: A scheme of an Electrospinning apparatus, making use of an elliptical collector 
Polymeric solution's characteristics (polymer's molecular weight, solution's viscosity, surface tension and conductivity, and solvents' dielectric properties), process parameters (voltage, solution's feedrate, temperature, collector's motion and/or shape, capillary diameter, and capillary tip -collector distance), and environmental conditions (humidity, temperature, atmosphere and pressure), are all factors that affect the morphological properties of the final fibers, mainly the diameters, length, presence of beads and orientation [17]. The process has been used to produce nanofibers from a wide range of polymers, and Table 1 shows those used to produce nanofibers for composite laminates reinforcing purposes, by considering the structure they were interleaved in (UD, PW or TW) and the main matrix reinforce (Carbon or Glass).

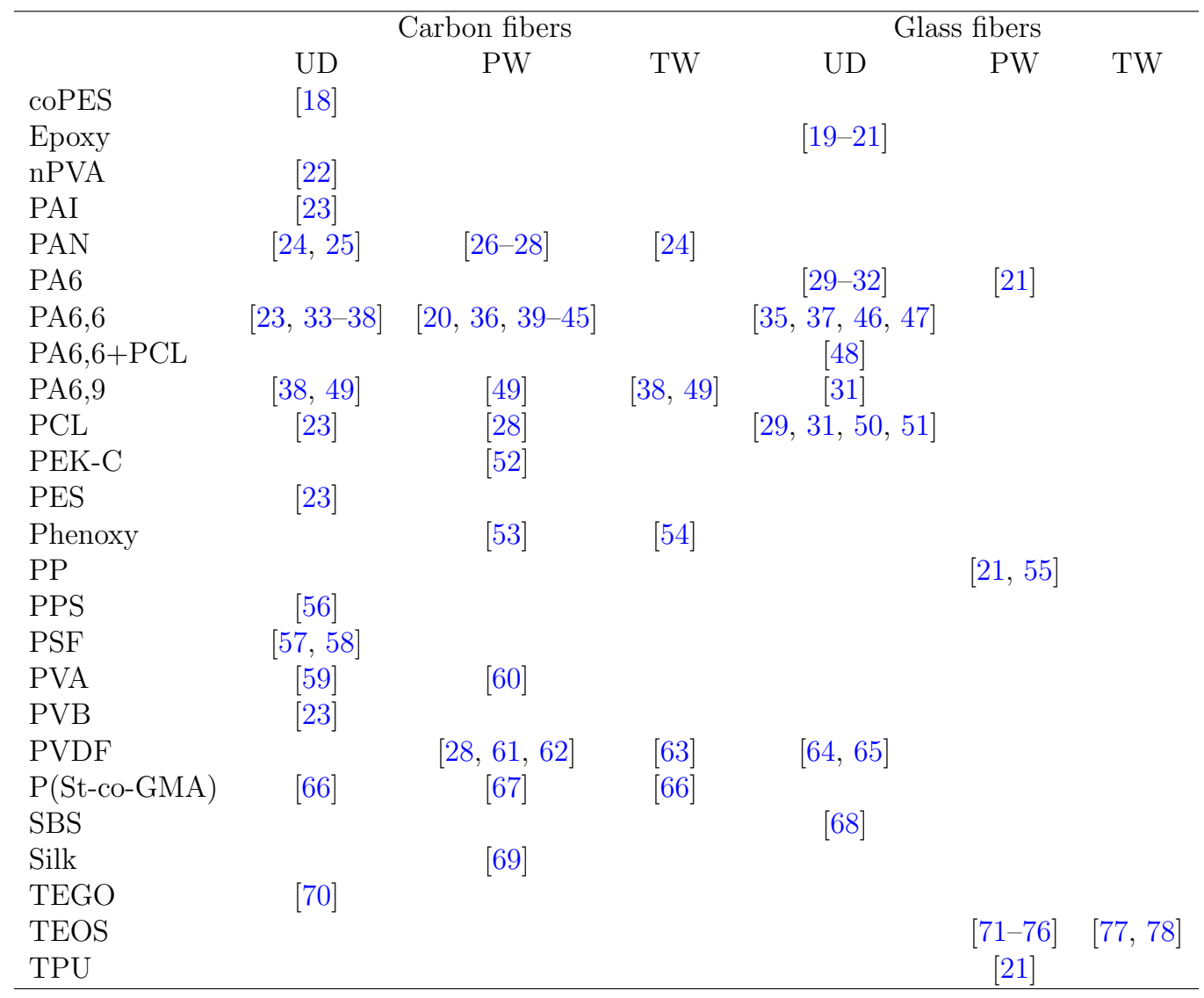

Table 1: Electrospun polymers and their application 
As seen, the most used polymer is the PA, sometimes also referred to with its commercial name: Nylon. The reasons for such popularity are due to that fact that it is relatively cheap, dissolves easily in a wide range of solvents, has better mechanical properties compared to other polymers at both bulk and nanofibrous level, and its melting point is usually higher than the maximum curing temperature of most of the matrix used for composites. This latter aspect makes the polymer morphologically stable during the curing process, and therefore the nanofibers maintain their geometry after the high-temperature and high-pressure cycles most composites have to go through to make the matrix polymerises.

From Table 1 it is also noteworthy that the vast majority of the nanofibers for reinforcing purposes are electrospun from thermoplastic polymers, and only few from thermosetting ones. In [79] it is shown that if a thermoplastic interleave (being particles, film of nanofibers) has a good bond with the composite's thermosetting resin, then it is possible to enhance the fracture toughness by various mechanisms. The same usually does not apply to thermosettings, and even when it does, the improvements are usually poorer than when the thermoplastics are employed.

Eventually, it is also worth mentioning that other types of interleaves rose popularity in the last few years, such as CNF and CNT [80-84] but they are not treated in this review. The main issues with the use of CNT and $\mathrm{CNF}$ are linked to health dangerousness [85] and difficulties in mixing and homogenizing with the matrix [86].

Authors considered out of the scope of this literature, and therefore did not treat, studies on nanofibers embedded in pure matrix [60, 87-94], on the single nanofiber [95-98], and on numerical simulations of nanomodified composites [65, 99-102].

\section{Electrospun nanofibers for structural reinforcement}

The present literature review reports and analyses the achievement in the field of electrospun nanofibers used as mechanical reinforcement in resinbased composite laminate materials. Nanofibrous mats are the ideal rein-

forcement to be interleaved between two plies of resin matrix composites because of the following main aspects:

1. thinness and lightness: nanomats can be as thin as few microns and as light as few grams per square meter, making their impact to weight and thickness of the final manufactured negligible; 
2. porosity: the high porosity of the mats makes the resin flow easily through them, still maintaining a solid bonding between the two layers the nanofibers are placed between in (see Figure 4);

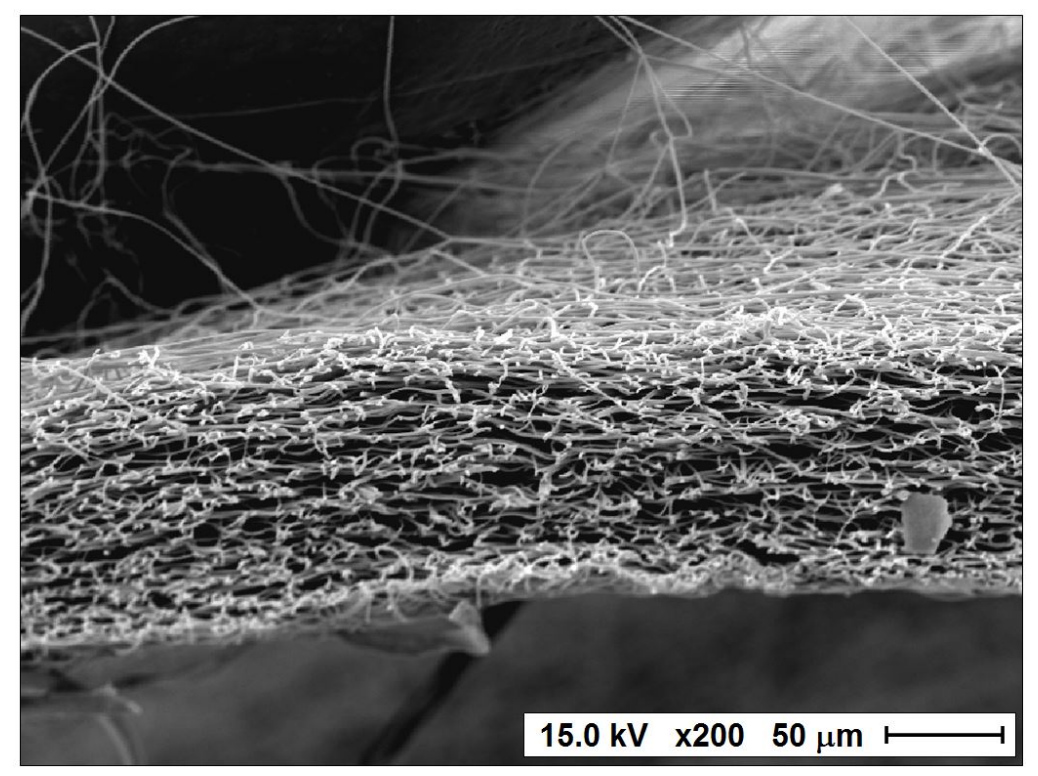

Figure 4: Section of a nanofibrous mat

3. tiny volume: the many pores of the nanomats, when interleaved, are filled with resin, and the actual volume of the nanofibers is small. The pressure applied during the curing process further shrinks the nanointerleave, and most of the papers did not register any appreciable thickness increase due to the interleave. However, in the majority of the papers, just one nanofibrous mat is used, and in some of those cases where several mats are applied, increases of few $\%$ are registered;

4. mechanical properties: nanofibers' mechanical properties can be significantly higher than those of the same material in bulk state [103].

Interleaving a nanofibrous mat into a laminate is one of the most critical phase when nanostructuring composites. Literature papers present two main approaches: $(i)$ direct electrospinning of nanofibers on the raw composite, or (ii) collection of the nanofibers on a support first, and then transfer to the composite. Each technique has its own pros and cons, and many aspects play an important role on the final results. Direct deposition presents advantages from the industrial implementation point of view, giving manufacturers the 
possibility of implementing the electrospinning process into the production lines, improving time to production and reducing costs; on the other end, collecting nanofibers on a metallic support gives engineers the possibility to obtain nanofibers of a wider range of properties and to use lower electrical fields due to the metallic nature of the collector. However, this review shows that no clear advantages can be seen of one method over the other regarding final composite's performances.

In both cases, once the nanofibers are applied to the composite, they get impregnated. Figure 5 shows two steps of such process. Nanofibers are laid on a prepreg lamina (see Figure A), and after few minutes the resin embeds the mat (see Figure B).
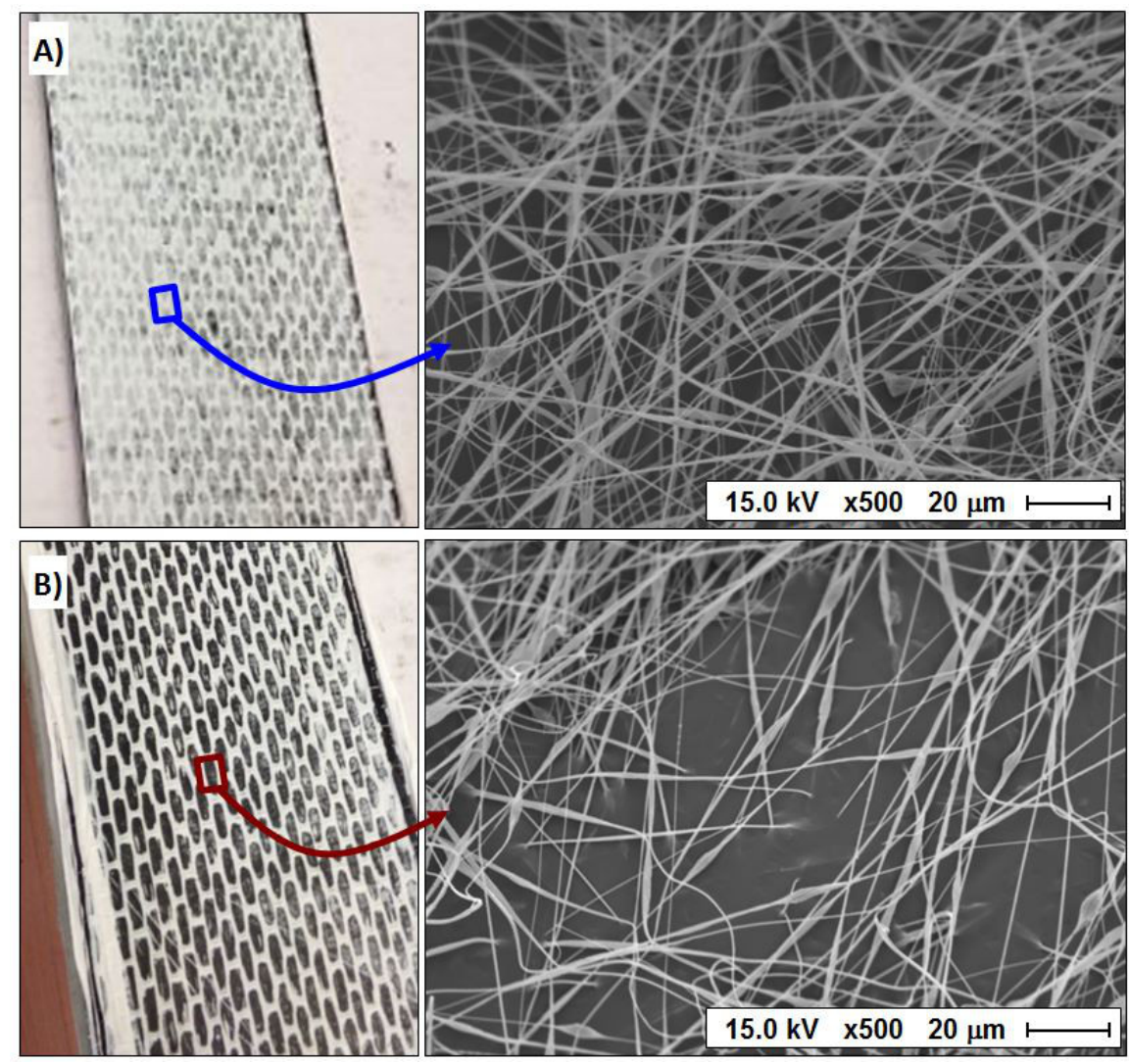

Figure 5: Nanofibers laid on a prepreg: initial time (A) and after few minutes (B)

For each type of load presented in next sections, the effect and the working mechanisms of the nanofibers have been presented, and Tables have been 
built to illustrate the main characteristics and results of the tested samples for each paper. Tables have 8 columns:

1. Ref\#: it indicates the paper each row is referred to;

2. Pol: it indicates the polymer(s) used to manufacture the nanofibers;

3. Solution: it indicate the composition of the polymeric solution that has been electropsun to produce the nanofibers;

4. $\mathrm{NF}_{\text {diam }}$ : it indicated the average diameter in $\mathrm{nm}$ of the nanofibers, end, when reported, the standard deviation;

5. NF amount: it indicated the amount of nanofibers interleaved in the specimens;

6. Man: it indicates the way the samples have been manufactured;

7. Layup: it indicates the layup the specimens are manufactured with. Comma (,) is used to separate orientation of consecutive UD layers, while slash $(/)$ separates the two orientation of a woven. E.g. a layup of $[0,90]$ refers to a laminate made of 2 layers, one of which oriented at 0 degrees, and the other at 90 degrees; a layup of [0/90] refers to a single-layer laminate, made of woven fabric, which fibers are oriented at 0 and 90 degrees;

8. Results: it indicates the most relevant results presented in the paper.

Mechanical experiments give important information on the effect of the nanofibers, but other techniques are also used to further investigate their working mechanisms and are here mentioned. Most of the papers use SEM images to study and compare virgin and nanomodified fractured surfaces; other common techniques used for the same purpose, and mentioned in this review are acoustic emissions [104], X-ray spectroscopy [82], high-resolution transmission electron microscopy [105] and transmission electron microscopy [13].

\subsection{Fracture mechanics}

Fracture mechanics is the most common and effective approach to investigate delamination behaviour of composites [106], and it mainly relays on Mode I and Mode II loading conditions [107]. As mentioned before, delamination takes place when a crack develops and propagates between two consecutive plies (the interlaminar region) usually filled with a thermosetting resin. The resin is a brittle material, which, once cracked, tends to make the delamination propagates rapidly. Under Mode I and Mode II fracture mechanic loading conditions, two consecutive plies of a laminate are 
made opening or sliding one over the other, respectively: applying a ductile, nanofibrous, interlayer in the delaminated region has proved to be a valid approach to mitigate delamination initiation and propagation since the very first publication on the topic [11].

The studies found in literature compare the results obtained from testing virgin (non-nanomodified) and nanomodified specimens with one or more delaminated interfaces and/or interleaved with nanofibers: comparing the results from both the configurations assesses the effectiveness of the nanoreinforce.

Force, displacement and crack propagation are usually recorded during the tests and used to evaluate the energy release rate at initiation $\left(\mathrm{G}_{\mathrm{C}}\right)$ and propagation $\left(\mathrm{G}_{\mathrm{R}}\right)$ of the delamination, and the fracture toughness of the material $(\mathrm{K})$.

Most of the experiments have been conducted under quasi static loading conditions (Tables 2a, 2b, 3a and 3b); only few authors tested samples under cycling loads (Tables $4 \mathrm{a}$ and $4 \mathrm{~b}$ ).

\subsubsection{Mode $I$}

Most of the Mode I fracture mechanics have been carried out under the guidelines provided in the ASTM D5528 [108]. From the mechanical tests, the critical and the propagation energy release rates and the fracture toughness are calculated, indicated with $\mathrm{G}_{\mathrm{I}, \mathrm{C}}, \mathrm{G}_{\mathrm{I}, \mathrm{R}}$ and $\mathrm{K}_{\mathrm{I}}$, respectively, where "I" indicated the Mode I.

Table 2 shows an overview of the 28 papers found in literature on this topic: 7 of them test glass fibers, 21 carbon fibers, mostly using PA as polymer for manufacturing nanofibers. 
(a) Glass fibers - Papers on Mode I

\begin{tabular}{|c|c|c|c|c|c|c|c|}
\hline $\begin{array}{l}\text { Ref \# } \\
{[29]}\end{array}$ & $\begin{array}{l}\text { Pol } \\
\text { PCL } \\
\text { PA6 }\end{array}$ & $\begin{array}{l}\text { Solution } \\
12 \% \text { in } 9: 1 \mathrm{FA}: \mathrm{AA} \\
16 \% \text { in 1:1 FA:AA }\end{array}$ & $\begin{array}{l}\mathbf{N F}_{\text {diam }} \\
343 \pm 150 \\
195 \pm 35\end{array}$ & $\begin{array}{l}\mathbf{N F} F_{\text {amount }} \\
5-15 \mathrm{~g} / \mathrm{m}^{2} \\
4-20 \mathrm{~g} / \mathrm{m}^{2}\end{array}$ & VARTM & $\begin{array}{l}\text { Layup } \\
{[0]_{8}}\end{array}$ & $\begin{array}{l}\text { Results } \\
\mathrm{G}_{\mathrm{I}, \mathrm{C}}:+50 \% \\
\mathrm{G}_{\mathrm{I}, \mathrm{C}}: \text { no variation }\end{array}$ \\
\hline$[30]$ & PA6 & $16 \%$ in $1: 1 \mathrm{FA}: \mathrm{AA}$ & $\begin{array}{l}150 \pm 19 \\
230 \pm 26\end{array}$ & $\begin{array}{l}5 \mathrm{~g} / \mathrm{m}^{2} \\
10 \mathrm{~g} / \mathrm{m}^{2}\end{array}$ & VARTM & {$[0,90]_{2 \mathrm{~s}}$} & $\begin{array}{l}\mathrm{G}_{\mathrm{I}, \mathrm{C}}:+14 \% \\
\mathrm{G}_{\mathrm{I}, \mathrm{C}}:-12 \%\end{array}$ \\
\hline$[46]$ & PA6,6 & $14 \%$ in $1: 1 \mathrm{FA}: \mathrm{CLF}$ & $150 \pm 15$ & $25 \pm 8 \mu \mathrm{m}\left(25 \mathrm{~g} / \mathrm{m}^{2}\right)$ & $\operatorname{PrP}$ & {$[0]_{10}$} & $\mathrm{G}_{\mathrm{I}, \mathrm{C}}:+62 \%$ \\
\hline [48] & $\begin{array}{l}\text { PA } 6,6 \\
\text { PCL } \\
\text { PA } 6,6+\text { PCL }\end{array}$ & $\begin{array}{l}14 \% \text { in } 1: 1 \mathrm{FA}: \mathrm{CLF} \\
15 \% \text { in } 1: 1 \mathrm{FA}: \mathrm{AA}\end{array}$ & $\begin{array}{l}270 \\
150\end{array}$ & $\begin{array}{l}27 \mu \mathrm{m} \\
31 \mu \mathrm{m} \\
30 \mu \mathrm{m}\end{array}$ & $\operatorname{PrP}$ & {$[0]_{14}$} & $\begin{array}{l}\mathrm{G}_{\mathrm{I}, \mathrm{C}}:+25 \% \\
\mathrm{G}_{\mathrm{I}, \mathrm{C}}:+4.5 \% \\
\mathrm{G}_{\mathrm{I}, \mathrm{C}}:+21 \%\end{array}$ \\
\hline [50] & PCL & $14 \mathrm{wt} \%$ in 1:1 FA:AA & $400 \pm 100$ & $\begin{array}{l}30-176 \mu \mathrm{m} \text { single layer } \\
17-89 \mu \mathrm{m} \text { double layer }\end{array}$ & $\operatorname{PrP}$ & {$[0]_{8}$} & $\begin{array}{l}\mathrm{G}_{\mathrm{I}, \mathrm{C}} / \mathrm{G}_{\mathrm{I}, \mathrm{R}}:+20 /+12 \% \\
\mathrm{G}_{\mathrm{I}, \mathrm{C}} / \mathrm{G}_{\mathrm{I}, \mathrm{R}}:+94 /+27 \%\end{array}$ \\
\hline [68] & SBS & BuAc:SBS:MTI-TAD:LiCl 100:13:0.0585:1.3 & $2000 \pm 500$ & $12-22 \mathrm{~g} / \mathrm{m}^{2}$ & VARTM & {$[0]_{8}$} & $\mathrm{G}_{\mathrm{I}, \mathrm{C}}:+90 \%$ \\
\hline$[73]$ & TEOS & {$[109]$} & 500 & NA & VARTM & {$[0 / 90]_{10}$} & $\mathrm{G}_{\mathrm{I}, \mathrm{C}}:-12 \%$ \\
\hline
\end{tabular}

(b) Carbon fibers - Papers on Mode I

\begin{tabular}{|c|c|c|c|c|c|c|c|}
\hline $\begin{array}{l}\text { Ref \# } \\
{[20]}\end{array}$ & $\begin{array}{l}\text { Pol } \\
\text { Epoxy } 609\end{array}$ & $\begin{array}{l}\text { Solution } \\
\text { 18-25\% in 3:1 MEK:PGME }\end{array}$ & $\begin{array}{l}\mathrm{NF}_{\text {diam }} \\
\mathrm{NA}\end{array}$ & $\begin{array}{l}\mathbf{N F}_{\text {amount }} \\
90,128,144,216 u m\end{array}$ & $\begin{array}{l}\text { Man } \\
\text { PrP }\end{array}$ & $\begin{array}{l}\text { Layup } \\
{[0]_{24}}\end{array}$ & $\begin{array}{l}\text { Results } \\
\text { no significant effects }\end{array}$ \\
\hline$[22]$ & nPVA & $16,18,20,22 \%$ in $\mathrm{H}_{2} \mathrm{O}$ & $40-80$ & NA & VARTM & {$[0 / 90]_{?}$} & $\begin{array}{l}\text { at } 0.1 \% \text { nPVA: } \\
\mathrm{G}_{\mathrm{I}, \mathrm{C}} / \mathrm{G}_{\mathrm{I}, \mathrm{R}}:+65 /+73 \%\end{array}$ \\
\hline [23] & $\begin{array}{l}\text { PCL } \\
\text { PES } \\
\text { PAI }\end{array}$ & $\begin{array}{l}15 \% \text { in } 68: 17 \mathrm{FA}: \mathrm{AA} \\
10 \% \text { in ETH } \\
10.6 \text { in ETH } \\
13 \% \text { in } 70: 17 \mathrm{FA}: \mathrm{AA} \\
20 \% \text { in DMA } \\
15 \% \text { in } 77: 8 \text { DMA:DMF }\end{array}$ & $\begin{array}{l}150-300 \\
400-700 \\
700-1000 \\
150-300 \\
150-300 \\
150-300\end{array}$ & $\begin{array}{l}1.5,4.5,9 \mathrm{~g} / \mathrm{m}^{2} \\
4.5 \mathrm{~g} / \mathrm{m}^{2} \\
4.3 \mathrm{~g} / \mathrm{m}^{2} \\
4.2 \mathrm{~g} / \mathrm{m}^{2} \\
3.6 \mathrm{~g} / \mathrm{m}^{2} \\
4.1 \mathrm{~g} / \mathrm{m}^{2}\end{array}$ & $\operatorname{PrP}$ & {$[0]_{12}$} & $\begin{array}{l}\mathrm{G}_{\mathrm{I}, \mathrm{C}} / \mathrm{G}_{\mathrm{I}, \mathrm{R}}:+33 /-6 \% \\
\mathrm{G}_{\mathrm{I}, \mathrm{C}} / \mathrm{G}_{\mathrm{I}, \mathrm{R}}:=13 /+4 \% \\
\mathrm{G}_{\mathrm{I}, \mathrm{C}} / \mathrm{G}_{\mathrm{I}, \mathrm{R}}:+16 /+11 \% \\
\mathrm{G}_{\mathrm{I}, \mathrm{C}} / \mathrm{G}_{\mathrm{I}, \mathrm{R}}:+3 /+12 \% \\
\mathrm{G}_{\mathrm{I}, \mathrm{C}} / \mathrm{G}_{\mathrm{I}, \mathrm{R}}:-52 /-52 \% \\
\mathrm{G}_{\mathrm{I}, \mathrm{C}} / \mathrm{G}_{\mathrm{I}, \mathrm{R}}:-58 /-68 \%\end{array}$ \\
\hline [28] & $\begin{array}{l}\text { PCL } \\
\text { PVDF } \\
\text { PAN }\end{array}$ & $\begin{array}{l}12-15-20 \% \text { in } 1: 1 \text { DMF:CHL } \\
16 \% \text { in } 1: 1 \text { DMF:AC } \\
13 \% \text { in DMF }\end{array}$ & $\begin{array}{l}103-125-210 \\
542 \\
607\end{array}$ & $0.2 \%$ & $\operatorname{PrP}$ & {$[0 / 90]_{4}$} & $\begin{array}{l}\mathrm{G}_{\mathrm{I}, \mathrm{C}}:+92 \% \text { with } 125 \mathrm{~nm} \text { PCL } \\
\mathrm{G}_{\mathrm{I}, \mathrm{R}}:+37 \% \text { with } 125 \mathrm{~nm} \text { PCL }\end{array}$ \\
\hline$[36]$ & PA6,6 & $12 \%$ in $3: 1$ FA:AA & $75-250$ & $1.6-2.0 \mathrm{~g} / \mathrm{m}^{2}$ & $\operatorname{PrP}$ & {$[0]_{20}$} & $\begin{array}{l}\mathrm{K}_{\mathrm{I}}:+150 \% \\
\mathrm{G}_{\mathrm{I}, \mathrm{C}} / \mathrm{G}_{\mathrm{I}, \mathrm{R}}:+152 /+31 \%\end{array}$ \\
\hline$[37]$ & PA6,6 & $20 \%$ in $70: 30$ TFA:FA & $350-400$ & $40,90 \mu \mathrm{m}$ & $\operatorname{PrP}$ & $\begin{array}{l}{[0]_{20}} \\
{[0 / 90]_{14}}\end{array}$ & $\begin{array}{l}\mathrm{G}_{\mathrm{I}, \mathrm{C}} / \mathrm{G}_{\mathrm{I}, \mathrm{R}}:+56 /+11 \% \\
\mathrm{G}_{\mathrm{I}, \mathrm{C}} / \mathrm{G}_{\mathrm{I}, \mathrm{R}}:+250 /+122 \%\end{array}$ \\
\hline [38] & $\begin{array}{l}\text { PA6, } 6 \\
\text { PA6,9 }\end{array}$ & $\begin{array}{l}14 \% 7: 3 \text { in FA:AA } \\
16 \% 1: 1 \text { in FA:AA }\end{array}$ & $\begin{array}{l}158 \pm 19 \\
245 \pm 28\end{array}$ & $3,18 \mathrm{~g} / \mathrm{m}^{2}$ & $\operatorname{PrP}$ & $\begin{array}{l}{[0]_{10}} \\
{[0 / 90]_{20}}\end{array}$ & $\begin{array}{l}\mathrm{G}_{\mathrm{I}, \mathrm{C}} / \mathrm{G}_{\mathrm{I}, \mathrm{R}}:+28 /-41 \% \\
\mathrm{G}_{\mathrm{I}, \mathrm{C}} / \mathrm{G}_{\mathrm{I}, \mathrm{R}}:+48 /+62 \%\end{array}$ \\
\hline [39] & PA & $20 \%$ in $1: 1$ FA:CLF & $400-650$ & $40 \mu \mathrm{m}\left(1.8 \mathrm{~g} / \mathrm{m}^{2}\right)$ & $\operatorname{PrP}$ & {$[0 / 90]_{14}$} & $\mathrm{G}_{\mathrm{I}, \mathrm{C}} / \mathrm{G}_{\mathrm{I}, \mathrm{R}}:+137 /+124 \%$ \\
\hline$[41]$ & PA6,6 & $14 \%$ in $1: 1 \mathrm{FA}: \mathrm{CLF}$ & $150 \pm 20$ & $25 \pm 8 \mu \mathrm{m}$ & $\operatorname{PrP}$ & {$[0 / 90]_{12}$} & $\mathrm{G}_{\mathrm{I}, \mathrm{C}}:+5 \%$ - Energy absorbed: $+23 \%$ \\
\hline [43] & PA6,6 & $20 \%$ in $7: 3$ TFE:FA & 500 & $70-100 \mu \mathrm{m}\left(8-12 \mathrm{~g} / \mathrm{m}^{2}\right)$ & $\operatorname{PrP}$ & {$[0 / 90]_{18}$} & $\mathrm{G}_{\mathrm{I}, \mathrm{C}}: 280-340 \%-\mathrm{G}_{\mathrm{I}, \mathrm{R}}: 255-322 \%$ \\
\hline [44] & PA6,6 & $14,25 \%$ in $1: 1 \mathrm{FA}: \mathrm{CLF}$ & 150,500 & $25,50 \mu \mathrm{m}$ & $\operatorname{PrP}$ & {$[0 / 90]_{20}$} & $\begin{array}{l}\text { best with thin nanoreinforce, random } \\
\text { nanofibers, small fiber diameter }\end{array}$ \\
\hline [53] & Phenoxy & $30 \%$ in $3: 7$ DMF:THF & $909 \pm 126$ & $70 \mu \mathrm{m}$ & $\operatorname{PrP}$ & {$[0 / 90]_{8}$} & $\mathrm{G}_{\mathrm{I}, \mathrm{C}} / \mathrm{G}_{\mathrm{I}, \mathrm{R}}:+98 /+106 \%$ \\
\hline$[54]$ & Phenoxy & $15 \%$ in $4: 1$ DMF:CHL & 700 & $35-150 \mu \mathrm{m}$ & RTM & {$[0 / 90]_{10}$} & $\mathrm{G}_{\mathrm{I}, \mathrm{C}} / \mathrm{G}_{\mathrm{I}, \mathrm{R}}:+325 /+300 \%$ \\
\hline$[57]$ & PSF & $25 \%$ in 9:1 DMAC:AC & 230 & $1,3,5 \%$ resin content & $\operatorname{PrP}$ & {$[0]_{24}$} & $\mathrm{G}_{\mathrm{I}, \mathrm{C}}:+158 /+261 /+281 \%$ with $1 / 3 / 5 \%$ \\
\hline [58] & PSF & $25 \%$ in 9:1 DMAC:AC & 230 & $5 \%$ resin content & $\operatorname{PrP}$ & $\mathrm{NA}$ & $\mathrm{G}_{\mathrm{I}, \mathrm{C}}: 280 \%$ \\
\hline [59] & PVA & $15 \%$ in $\mathrm{H}_{2} \mathrm{O}$ & $329 \pm 58$ & $7.10 \pm 0.70 \mathrm{~g} / \mathrm{m}^{2}$ & VARTM & {$[0]_{4}$} & $\mathrm{G}_{\mathrm{I}, \mathrm{C}}:-27 \%$ \\
\hline [61] & $\begin{array}{l}\text { HMV PVDF } \\
\text { LMW PVDF }\end{array}$ & $\begin{array}{l}25 \% \text { in NA } \\
30 \% \text { in NA }\end{array}$ & $\begin{array}{l}213 \pm 70 \\
340 \pm 150\end{array}$ & $5 \%$ resin content & $\operatorname{PrP}$ & {$[0 / 90]_{8}$} & $\begin{array}{l}\mathrm{G}_{\mathrm{I}, \mathrm{C}} / \mathrm{F}_{\max }:-20 /+6.0 \% \\
\mathrm{G}_{\mathrm{I}, \mathrm{C}} / \mathrm{F}_{\max }:-20+3.6 \%\end{array}$ \\
\hline [62] & PVDF & $15 \%$ in $7: 3$ DMSO:AC & $500 \pm 110$ & $45 \pm 5$ & $\operatorname{PrP}$ & {$[0 / 90]_{14}$} & $\mathrm{G}_{\mathrm{I}, \mathrm{C}} / \mathrm{G}_{\mathrm{I}, \mathrm{R}} / \mathrm{F}_{\max }:+98 /+73 /+36 \%$ \\
\hline$[63]$ & PVDF & $15 \%$ in 3:7 DMSO:AC & $500 \pm 110$ & $30 \pm 3 \mu \mathrm{m}$ & $\operatorname{PrP}$ & {$[0 / 90]_{14}$} & $\mathrm{G}_{\mathrm{I}, \mathrm{C}} / \mathrm{G}_{\mathrm{I}, \mathrm{R}}:+43 /+36 \%$ \\
\hline [65] & PVDF & $15 \%$ in $3: 7$ DMSO:AC & $500 \pm 110$ & $\begin{array}{l}30 \pm 3 \mu \mathrm{m} \\
60 \pm 5 \mu \mathrm{m}\end{array}$ & $\operatorname{PrP}$ & {$[0 / 90]_{14}$} & $\begin{array}{l}\mathrm{G}_{\mathrm{I}, \mathrm{C}}:+44 \% \\
\mathrm{G}_{\mathrm{I}, \mathrm{C}}:+88 \%\end{array}$ \\
\hline [93] & PA6,6 & $14 \%$ in 1:1 FA:CLF & $170 \pm 30$ & $70-100 \mu \mathrm{m}$ & $\operatorname{PrP}$ & {$[0]_{10}$} & $\mathrm{G}_{\mathrm{I}, \mathrm{C}} / \mathrm{G}_{\mathrm{I}, \mathrm{R}}:+23 /-22 \%$ \\
\hline
\end{tabular}

Table 2: Papers on Mode I tests

The most-right column of the table indicates that interleaving nanofibers into composites introduce significant benefits in the vast majority of the 
cases. Figure 6 and Figure 7, show experimental results plotted in terms of $\mathrm{G}_{\text {Nanomodified vs. }} \mathrm{G}_{\text {Virgin }}$ for Glass and Carbon fibers specimens, respectively, providing a clear and immediate understanding of the effect obtained by interleaving laminate's interfaces with nanofibers. The solid lines identify configurations with identical virgin and nanomodified energy release rates; all the points above (below) these lines identify experiments with improved (reduced) Mode I energy release rate, due to the use of nanofibers.

Figure 6 shows that only 2 out of 14 sets of experiments ( $14.3 \%$ of the total) on glass fiber specimens resulted in a reduction of energy release rates when nanofibers are employed. In the other 12 sets ( $85.7 \%$ of the total), nanofibers had positive (11 cases, $78.6 \%$ of the total) or negligible ( 1 case, $7.1 \%$ ) effects on the performances of the samples. The highest registered improvement was 94\% (UD glass fibers, PCL nanofibers, [50]).

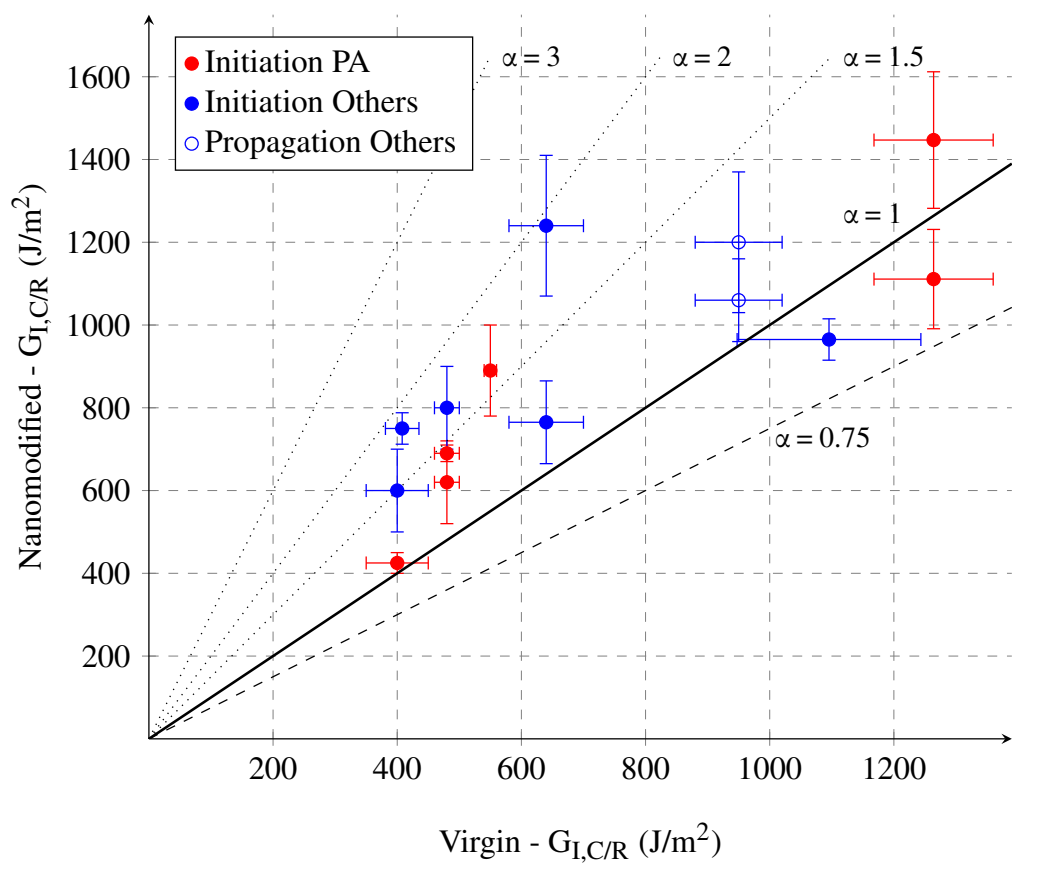

Figure 6: Mode I energy release rates for GFRP. $\alpha=\frac{G_{\text {Nanomodified }}}{G_{\text {Virgin }}}$. No data available on crack propagation for PA-modified specimens

Given the larger number of papers found for carbon fibers, Figure 7 has been split in two: Figures 7a and 7b show delamination's initiation and propagation's results, respectively. Furthermore, due to the large numeber 
of paper using PA and PVDF nanofibers compared to the other polymers, these are indicated with a different colors, as shown in the legends. Results from [20] have been omitted because authors only test one sample per configuration, and the results lack on statistical significance.

Similarly to what has been said for glass fiber samples, the vast majority of the results $(82.5 \%)$ report a non-negative effect of the nanointerleave, and only $17.5 \%$ of the cases shows a reduction of properties. $\mathrm{G}_{\mathrm{I}, \mathrm{C}}$ and $\mathrm{G}_{\mathrm{I}, \mathrm{R}}$ of nanomodified specimens has been registered up to 4 times higher than pristine ones ([54], Phenoxy resin as polymer for the nanofibers). 


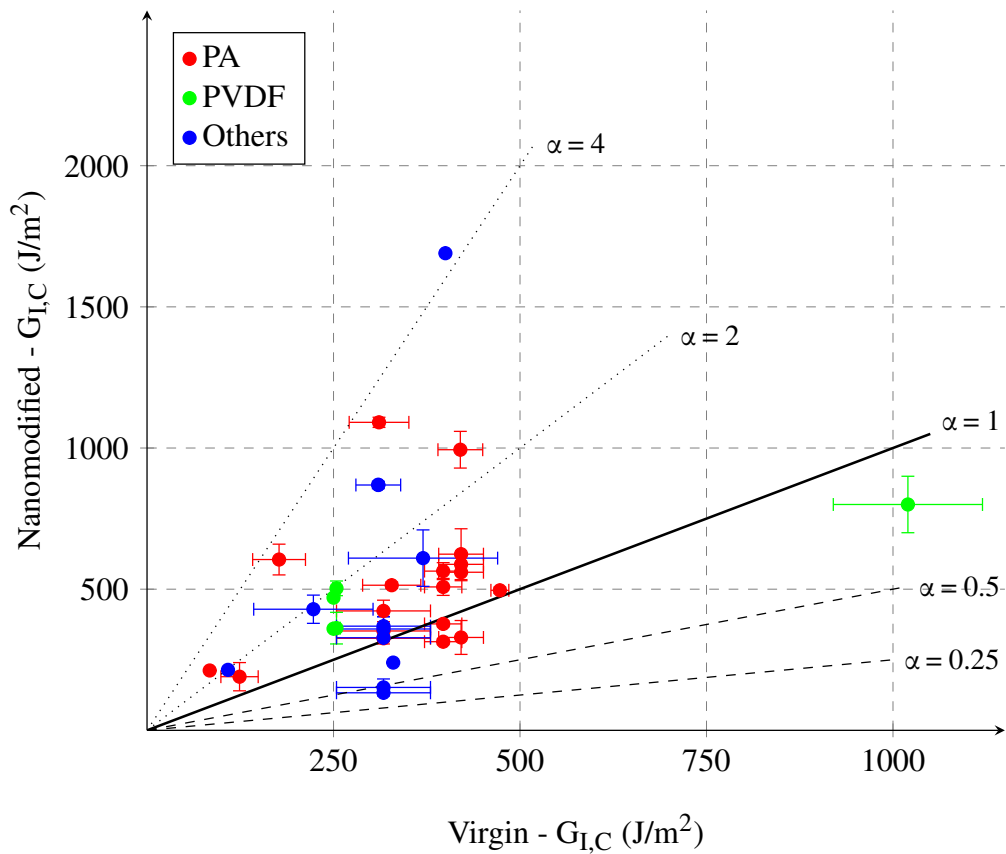

(a) $\mathrm{G}_{\mathrm{I}, \mathrm{C}}$

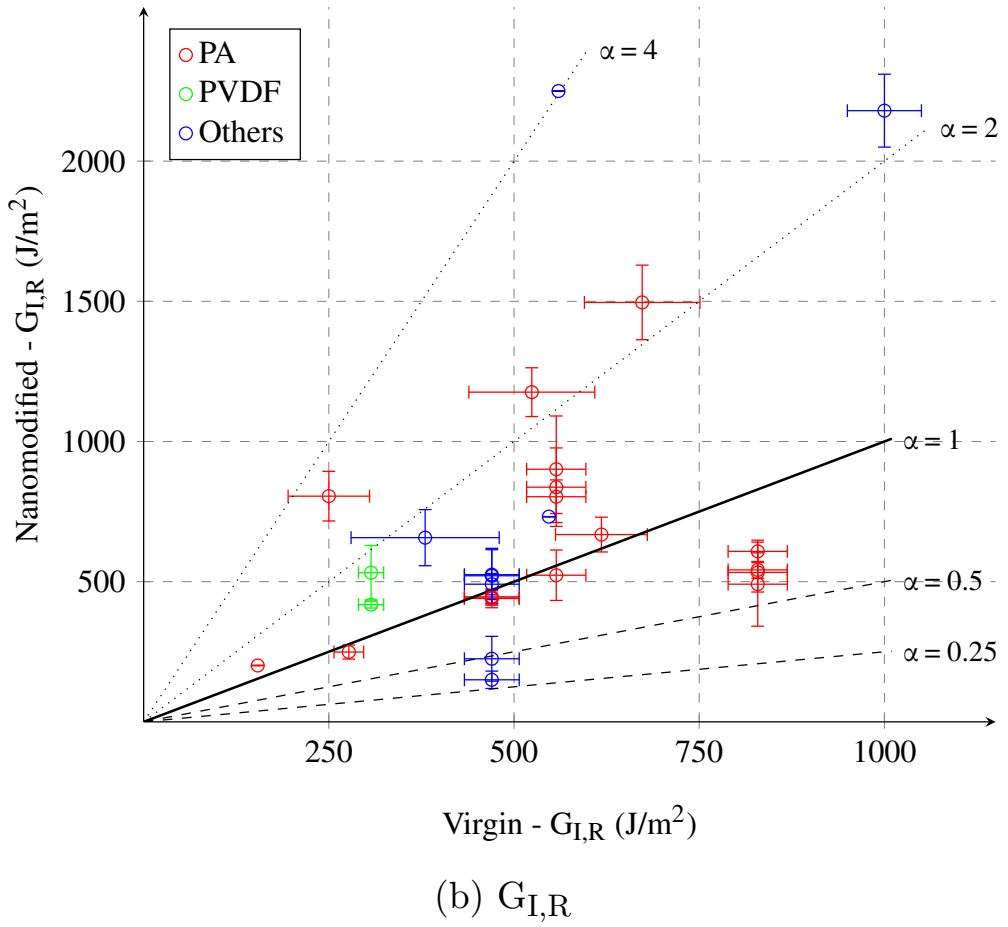

Figure 7: Mode I energy release rates for CFRP. $\alpha=\frac{G_{\text {Nanomodified }}}{G_{\text {Virgin }}}$ 
Figure 7 shows similar result distributions for initiation and propagation: most of the improvements are clustered in the area $1<\alpha<2$, followed by the $2<\alpha<3$. The aspect of major concern is that of delamination initiation, for when a crack starts, it is easier to propagate and the laminates is compromised and unrepairable; on the other end, reducing the crack propagation improves the safety of the component, and increases its use-life. Several reinforce mechanism have been discovered by the authors, and are here presented, with focus to the crack's initiation and the propagation phases:

- nanofiber bridging [14, 25, 29, 37, 38, 46, 68, 69], mostly found when using ductile PA nanofibers. The phenomenon is well presented in [29], where authors present a detailed analysis of the fracture surface of their tested samples, using SEM: an extensive interlaminar crossings have been observed, besides the usual glass fiber-epoxy debonding. Interlaminar crossing happens when a crack propagates inside the same interlaminar region (between the same plies), but moving from one side of the nanointerlayer to the other passing through it. When this happens, some nanofibers survive intact, and they are those that are still able to connect the two sides of the crack, increasing the residual interlaminar's fracture toughness. It is easy to understand that it is a phenomenon that mitigates the delamination propagation, improving the $\mathrm{G}_{\mathrm{II}}$ of the laminate, compared to the control samples;

- resin reinforcement [23, 60, 87-94], detected by several authors, using a different type of polymers. In [94] it is demonstrated that using an hybrid electrospinning-electrospraying method (electrospraying uses polymers with much shorter chains which end deposited as particles rather than fibers), a resin containing $0.13 \%$ weight content of fiber was $700 \%$ stronger, $250 \%$ stiffer, and more ductile than the non-modified one. As mentioned by few authors [89, 91, 93], a main aspect to take into consideration when interleaving nanofibers in a laminate is their adhesion with the resin: it is affected by several factors (moisture of the nanofibers, process conditions such as pressure, temperature, and vacuum grade, etc.) and strongly influences the final performances of the laminate. Resin reinforcement is the most desirable reinforce mechanism, for it actively reduces the risk of crack initiation, and developing an optimum, repeatable and reliable interleaving process that realise a good bonding between the nanofibers and the resin is crucial for a 
positive effect of the reinforcement. Similar conclusions are drawn in [23], where authors identify in the nanofibers-resin compatibility one of the main reason of the better properties they found for nanomodified samples;

- crack path modification [37, 39, 45, 62, 93], observed mainly when using PA nanofibers, but also with phenoxy, PCL and PSF. Those papers investigating the crack path during delamination propagation, discovered that the presence of nanofibers hinders the motion of the crack, which is then forced to follow tortuous path, thus increasing the energy required to propagate, compared with a neat interface. It is one the most effective reinforce mechanism to hinder crack propagation, for it force the delamination to follow longer and harder paths, sometimes also crossing plies [45].

It is worth mentioning that among all papers, only one used a combination of polymers [48]: PCL and PA6,6. Those two polymers have different glass transition temperatures resulting in PCL nanofibers melting during curing cycles. The PSU-modified epoxy matrix has lower rigidity and strength compared to neat matrix, but higher fracture toughness [110], and at the same time PA kept its properties: as a result, the combination of two types of nanofibers efficiently reinforced the sample under both Modes I and II loading types.

\subsubsection{Mode $I I$}

Mode II fracture mechanics has been standardised only in 2014 [111], and most of the earlier works found in literature refer to either other papers, or to the guidelines provided by the European Structural Integrity Society [112].

Different kinds of tests can be found for investigating Mode II fracture mechanics such as ENF, ISS and SBSh; for all the cases the specimen is predelaminated, with the purpose of generating concentrated shear stress at the crack tip. The critical and propagation energy release rates and the fracture toughness are indicated with $\mathrm{G}_{\mathrm{II}, \mathrm{C}}, \mathrm{G}_{\mathrm{II}, \mathrm{R}}$ and $\mathrm{K}_{\mathrm{II}}$, respectively, where "II" indicates the loading Mode II.

Table 3 shows an overview of the 18 papers found in literature studying Mode II fracture mechanics on nanomodified samples: carbon and glass fibers are investigated in the same number of papers (9), and the most used polymer is PA. 
(a) Glass fibers - Papers on Mode II

\begin{tabular}{|c|c|c|c|c|c|c|c|}
\hline $\begin{array}{l}\text { Ref \# } \\
{[19]}\end{array}$ & Epoxy & $\begin{array}{l}\text { Solution } \\
\text { 18-25\% in 3:1 MEK:PGME }\end{array}$ & $\mathbf{N F}_{\text {diam }}$ & $\begin{array}{l}\mathbf{N F} F_{\text {amount }} \\
80-257 \mu \mathrm{m}\end{array}$ & $\begin{array}{l}\text { Man } \\
\operatorname{PrP}\end{array}$ & $\begin{array}{l}\text { Layup } \\
{[0]_{24}}\end{array}$ & $\begin{array}{l}\text { Results } \\
\mathrm{G}_{\mathrm{II}, \mathrm{C}} \text { from }-41 \% \text { to }+17 \% \\
\mathrm{G}_{\mathrm{II}, \mathrm{C}}, \mathrm{F} \text { max at } 0.1281 \mathrm{~mm} \text { nanomat thick }\end{array}$ \\
\hline [29] & $\begin{array}{l}\text { PCL } \\
\text { PA6 } 6\end{array}$ & $\begin{array}{l}12 \% \text { in } 9: 1 \text { FA:AA } \\
16 \% \text { in 1:1 FA:AA }\end{array}$ & $\begin{array}{l}343 \pm 150 \\
195 \pm 35\end{array}$ & $\begin{array}{l}5-15 \mathrm{~g} / \mathrm{m}^{2} \\
4-20 \mathrm{~g} / \mathrm{m}^{2}\end{array}$ & VARTM & {$[0]_{8}$} & $\begin{array}{l}\mathrm{G}_{\mathrm{II}, \mathrm{C}}:+81 \% \\
\mathrm{G}_{\mathrm{II}, \mathrm{C}}:+76 \%\end{array}$ \\
\hline [31] & $\begin{array}{l}\text { PCL } \\
\text { PA6 } \\
\text { PA6,9 }\end{array}$ & 1:1 FA:AA & $\begin{array}{l}650 \pm 150 \\
195 \pm 35 \\
250 \pm 30\end{array}$ & $14 \pm 0.5 \mathrm{~g} / \mathrm{m}^{2}$ & VARTM & {$[0]_{8}$} & $\begin{array}{l}\mathrm{G}_{\mathrm{II}, \mathrm{C}}:+25 /+42 \% \text { CCP } / \mathrm{ENF} \\
\mathrm{G}_{\mathrm{II}, \mathrm{C}}:+28 /+30 \% \text { CCP } / \mathrm{ENF} \\
\mathrm{G}_{\mathrm{II}, \mathrm{C}}:+31 /+46 \% \text { CCP } / \mathrm{ENF}\end{array}$ \\
\hline [35] & PA6,6 & $14 \%$ in $1: 1 \mathrm{FA}: \mathrm{CLF}$ & 100 & $9 \mathrm{~g} / \mathrm{m}^{2}$ & $\operatorname{PrP}$ & $\begin{array}{l}{[0]_{10}} \\
{[0]_{16}} \\
{[0]_{18}}\end{array}$ & $\begin{array}{l}\mathrm{G}_{\mathrm{II}, \mathrm{C}}:+85 \% \\
\mathrm{G}_{\mathrm{II}, \mathrm{C}}:+75 \% \\
\text { no effect }\end{array}$ \\
\hline [46] & PA6,6 & $14 \%$ in $1: 1 \mathrm{FA}: \mathrm{CLF}$ & $150 \pm 15$ & $25 \pm 8 \mu \mathrm{m}\left(25 \mathrm{~g} / \mathrm{m}^{2}\right)$ & $\operatorname{PrP}$ & {$[0]_{10}$} & $\mathrm{G}_{\mathrm{II}, \mathrm{C}}:+109 \%$ \\
\hline [48] & $\begin{array}{l}\text { PA6,6 } \\
\text { PCL } \\
\text { PA6,6+PCL }\end{array}$ & $\begin{array}{l}14 \% \text { in } 1: 1 \mathrm{FA}: \mathrm{CLF} \\
15 \% \text { in } 1: 1 \mathrm{FA}: \mathrm{AA}\end{array}$ & $\begin{array}{l}270 \\
150\end{array}$ & $\begin{array}{l}27 \mu \mathrm{m} \\
31 \mu \mathrm{m} \\
30 \mu \mathrm{m}\end{array}$ & $\operatorname{PrP}$ & {$[0]_{16}$} & $\begin{array}{l}\mathrm{G}_{\mathrm{II}, \mathrm{C}}:+24 \% \\
\mathrm{G}_{\mathrm{II}, \mathrm{C}}:+68 \% \\
\mathrm{G}_{\mathrm{II}, \mathrm{C}}:+56 \%\end{array}$ \\
\hline [49] & PA6,9 & $20 \%$ in 1:1 FA:AA & $\begin{array}{l}457 \pm 53 \text { random } \\
464 \pm 110 \text { aligned }\end{array}$ & $11 \pm 0.5 \mathrm{~g} / \mathrm{m}^{2}$ & PrP & {$[0]_{12}$} & $\mathrm{G}_{\mathrm{II}, \mathrm{C}}:+400 \%$ \\
\hline [68] & SBS & BuAc:SBS:MTI-TAD:LiCl in 100:13:0.0585:1.3 & $2000 \pm 500$ & $12-22 \mathrm{~g} / \mathrm{m}^{2}$ & VARTM & {$[0]_{8}$} & $\mathrm{G}_{\mathrm{II}, \mathrm{C}}:+100 \%$ \\
\hline [71] & TEOS & see reference & 200 & $6 \mu \mathrm{m}\left(2.5 \mathrm{~g} / \mathrm{m}^{2}\right)$ & VARTM & {$[0 / 90]_{6}$} & $\mathrm{G}_{\text {II,C }}:+56.1 \%$ \\
\hline
\end{tabular}

(b) Carbon fibers - Papers on Mode II

\begin{tabular}{|c|c|c|c|c|c|c|c|}
\hline Ref \# & Pol & Solution & $\mathrm{NF}_{\text {diam }}$ & $\mathbf{N F}_{\text {amount }}$ & Man & Layup & Results \\
\hline \multirow{6}{*}{ [23] } & PA6,6 & $15 \%$ in $68: 17 \mathrm{FA}: \mathrm{AA}$ & $150-300$ & $1.5,4.5,9 \mathrm{~g} / \mathrm{m}^{2}$ & \multirow{6}{*}{$\operatorname{PrP}$} & \multirow{6}{*}[0]{$_{12}$} & $\mathrm{G}_{\mathrm{II}, \mathrm{C}}:+29,69,54 \%$ with $\mathrm{NF}_{\text {amount }}$ \\
\hline & PVB & $10 \%$ in ETH & $400-700$ & $4.5 \mathrm{~g} / \mathrm{m}^{2}$ & & & $\mathrm{G}_{\mathrm{II}, \mathrm{C}}:-6 \%$ \\
\hline & & $10 \%$ in ETH & $700-1000$ & $4.3 \mathrm{~g} / \mathrm{m}^{2}$ & & & $\mathrm{G}_{\mathrm{II}, \mathrm{C}}:-8 \%$ \\
\hline & PCL & $13 \%$ in $70: 17 \mathrm{FA}: \mathrm{AA}$ & $150-300$ & $4.2 \mathrm{~g} / \mathrm{m}^{2}$ & & & $\mathrm{G}_{I I, C}:+7 \%$ \\
\hline & PES & $20 \%$ in DMA & $150-300$ & $3.6 \mathrm{~g} / \mathrm{m}^{2}$ & & & $\mathrm{G}_{\mathrm{II}, \mathrm{C}}:+20 \%$ \\
\hline & PAI & $15 \%$ in $77: 8$ DMA:DMF & $150-300$ & $4.1 \mathrm{~g} / \mathrm{m}^{2}$ & & & $\mathrm{G}_{\mathrm{II}, \mathrm{C}}:+56 \%$ \\
\hline [35] & PA6,6 & $14 \%$ in 1:1 FA:CLF & 100 & $9 \mathrm{~g} / \mathrm{m}^{2}$ & $\operatorname{PrP}$ & {$[0]_{18}$} & no significant effect \\
\hline$[37]$ & $\mathrm{PA} 6,6$ & $20 \%$ in $70: 30$ TFA:FA & $350-400$ & $40,90 \mu \mathrm{m}$ & $\operatorname{PrP}$ & $\begin{array}{l}{[0]_{20}} \\
{[0 / 90]_{14}}\end{array}$ & $\begin{array}{l}\mathrm{G}_{\mathrm{II}, \mathrm{C}}:+62 \% \\
\mathrm{G}_{\mathrm{II}, \mathrm{C}} / \mathrm{G}_{\mathrm{II}, \mathrm{R}}:+99 /+34 \%\end{array}$ \\
\hline [38] & $\begin{array}{l}\text { PA6,6 } \\
\text { PA6,9 }\end{array}$ & $\begin{array}{l}14 \% 7: 3 \text { in FA:AA } \\
16 \% 1: 1 \text { in FA:AA }\end{array}$ & $\begin{array}{l}158 \pm 19 \\
245 \pm 28\end{array}$ & $3,18 \mathrm{~g} / \mathrm{m}^{2}$ & $\operatorname{PrP}$ & $\begin{array}{l}{[0]_{10}} \\
{[0 / 90]_{20}}\end{array}$ & $\begin{array}{l}\mathrm{G}_{\mathrm{II}, \mathrm{C}} / \mathrm{G}_{\mathrm{II}, \mathrm{R}}:+20 /+211 \% \\
\mathrm{G}_{\mathrm{II}, \mathrm{C}} / \mathrm{G}_{\mathrm{I}, \mathrm{R}}:+211 /+65 \%\end{array}$ \\
\hline [41] & PA6,6 & $14 \%$ in 1:1 FA:CLF & $150 \pm 20$ & $25 \pm 8 \mu \mathrm{m}$ & $\operatorname{PrP}$ & {$[0 / 90]_{12}$} & $\sigma_{\max }:+6.5 \%$ - Absorbed energy: $+8.1 \%$ \\
\hline [44] & $\mathrm{PA} 6,6$ & $14,25 \%$ in $1: 1 \mathrm{FA}: \mathrm{CLF}$ & 150,500 & $25,50 \mu \mathrm{m}$ & $\operatorname{PrP}$ & {$[0 / 90]_{20}$} & $\begin{array}{l}\text { no thickness effect, aligned nanofibers, } \\
\text { smaller nanofibers improved absorbed energy, } \\
\text { bigger diameters improved the maximum tension }\end{array}$ \\
\hline [53] & Phenoxy & $30 \%$ in $3: 7$ DMF:THF & $909 \pm 126$ & $70 \mu \mathrm{m}$ & $\operatorname{PrP}$ & {$[0 / 90]_{8}$} & $\mathrm{G}_{\mathrm{II}, \mathrm{C}}:+31 \%$ \\
\hline [61] & $\begin{array}{l}\text { HMV PVDF } \\
\text { LMW PVDF }\end{array}$ & $\begin{array}{l}25 \% \text { in } 8: 2 \text { DMF:AC } \\
30 \%\end{array}$ & $\begin{array}{l}213 \pm 70 \\
340 \pm 150\end{array}$ & $5 \%$ resin content & $\operatorname{PrP}$ & {$[0 / 90]_{8}$} & $\mathrm{G}_{\mathrm{II}, \mathrm{C}}:+57 \%$ \\
\hline [69] & Silk & $13 \%$ in FA & $50-100$ & $0,3,5,10 \%$ oo resin content & VARTM & {$[0 / 90]_{10}$} & $\mathrm{G}_{\mathrm{II}, \mathrm{C}}:+30 \%$ at $5 \%$ \\
\hline
\end{tabular}

Table 3: Papers on Mode II tests

Similarly to the Mode I, also for the Mode II a general improvement can be observed due to the use of the nanofibers.

Figure 8 presents the results on tests on GFRP: only 1 out of 20 sets of experiments resulted in a clear reduction of properties. In the other 19 sets ( $95 \%$ of the total), the researchers found positive (15 cases, $75 \%$ of the total) or unclear (4 case, 20\%) effects resulting from the interleaved nanofibers. Properties' improvement up to 3 times have been registered (TW carbon fibers, PA6,9 nanofibers, [49]).

Results generally show a low standard deviation, but in [19]; unfortunately the authors have not provided an explanation for the large scatter they found. It is worth mentioning that no papers have been found dealing with Mode 
II delamination propagation in glass fiber samples, probably due to the fact that it happens suddenly and it is difficult to register.

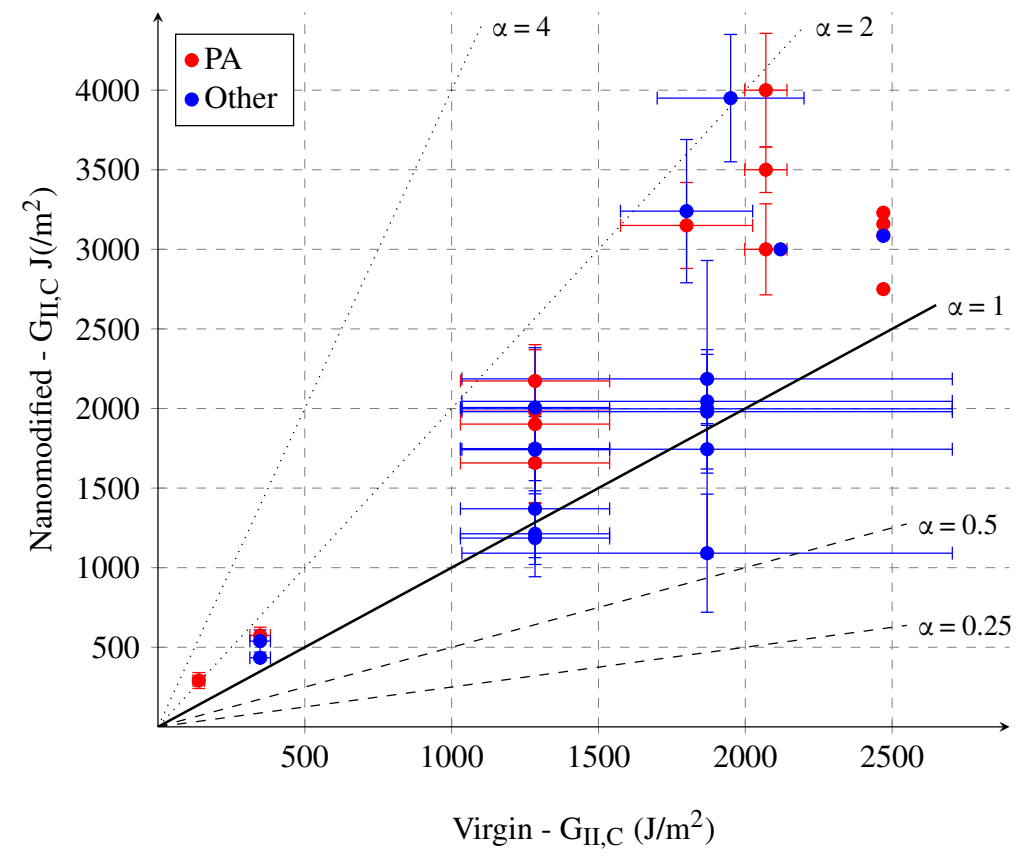

Figure 8: Mode II energy release rates for GFRP. $\alpha=\frac{G_{\text {Nanomodified }}}{G_{\text {Virgin }}}$

Similar results can be found in Figure 9 on carbon fibers' samples: nanofibers improved the energy release rate at delamination initiation in 18 cases out of $21(85.7 \%)$, and in 3 cases (14.3\%) results were unclear. No clear detrimental results have been found.

By comparing Mode I and Mode II results it appears that nanofibers are more effective in the latter case. 


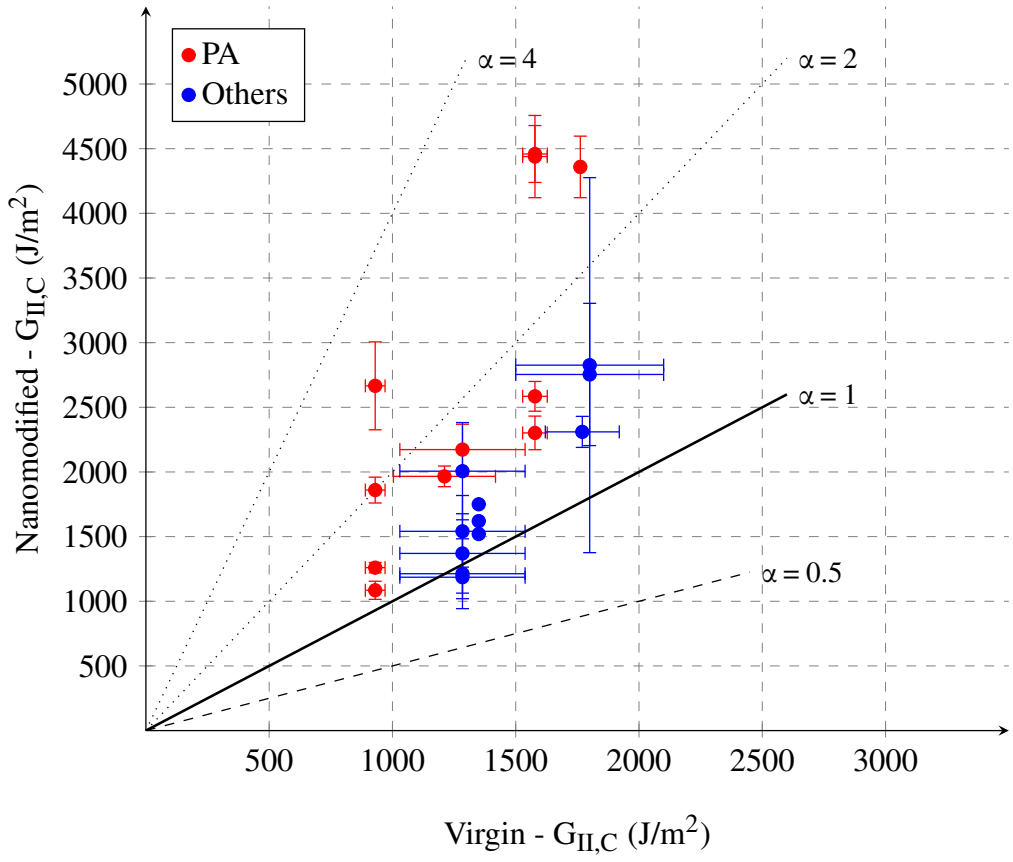

(a) $\mathrm{G}_{\mathrm{II}, \mathrm{C}}$

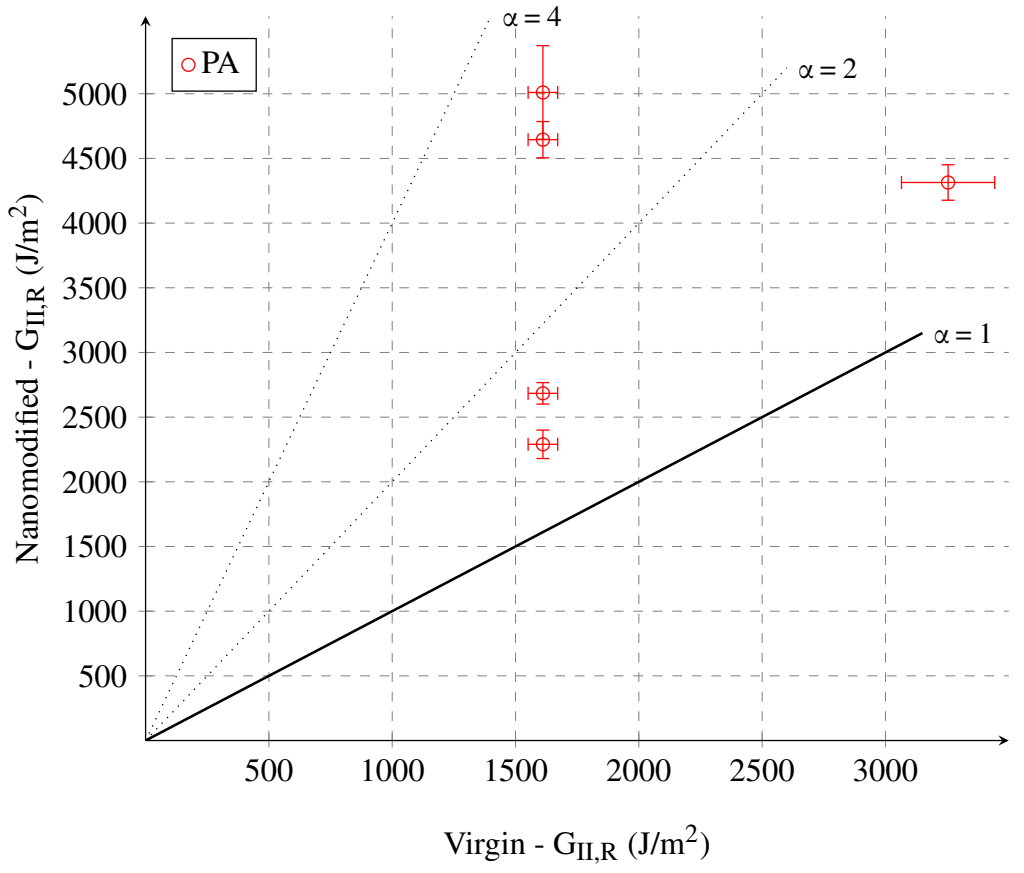

(b) $\mathrm{G}_{\mathrm{II}, \mathrm{R}}$

Figure 9: Mode II energy release rates for CFRP. $\alpha=\frac{G_{\text {Nanomodified }}}{G_{\text {Virgin }}}$ 21 
In Mode II fracture mechanic tests, the delamination grows between two interfaces sliding one over the other in opposite directions. Nanofibers are placed at least into the delaminated interfaces, and it has been widely recognised that they bring a strong positive effect into the laminates. Authors' results showed the same reinforcing mechanism already presented for Mode I:

- crack path modification, detected in [19, 29, 31, 37, 48, 49, 68];

- nanofiber bridging, in [29, 31, 38, 46, 49];

- matrix reinforcing, in [23, 37, 53].

\subsubsection{Fracture mechanics under fatigue loads}

Only 5 papers have been found on fatigue tests of nanomodified composites: one testing GFRP under Mode II, and 4 testing CFRP under Mode I, as shown in Table 4.

(a) Glass fibers - Papers on Fatigue Mode II

\begin{tabular}{|c|c|c|c|c|c|c|c|}
\hline Ref \# & Pol & Solution & $\mathbf{N F}_{\text {diam }}$ & $\mathbf{N F}_{\text {amount }}$ & Man & Layup & Results \\
\hline [31] & $\begin{array}{l}\text { PCL } \\
\text { PA6 } \\
\text { PA6.9 }\end{array}$ & NA $\%$ in $1: 1 \mathrm{FA}: \mathrm{AA}$ & $\begin{array}{l}650 \pm 150 \\
195 \pm 35 \\
250 \pm 30\end{array}$ & $14 \pm 0.5 \mathrm{~g} / \mathrm{m}^{2}$ & VARTM & {$[0]_{8}$} & $\begin{array}{l}\text { CCP: PCL best results } \\
\text { ENF: Growth rate: }-15 \text { times }\end{array}$ \\
\hline
\end{tabular}

(b) Carbon fibers - Papers on Fatigue Mode I

\begin{tabular}{llllllll}
\hline $\begin{array}{l}\text { Ref \# } \\
{[22]}\end{array}$ & $\begin{array}{l}\text { Pol } \\
\text { nPVA }\end{array}$ & $\begin{array}{l}\text { Solution } \\
16,18,20,22 \% \text { in } \mathrm{H}_{2} \mathrm{O}\end{array}$ & $\begin{array}{l}\mathrm{NF}_{\text {diam }} \\
40-80\end{array}$ & $\begin{array}{l}\mathbf{N F}_{\text {amount }} \\
\text { mixed into epoxy }\end{array}$ & $\begin{array}{l}\text { Man } \\
\text { VARTM }\end{array}$ & $\begin{array}{l}\text { Layup } \\
{[0 / 90]_{\text {? }}}\end{array}$ & $\begin{array}{l}\text { Results } \\
\text { at } 0.1 \% \mathrm{nPVA} \\
\text { Fatigue life: } 10-30 \text { times longer }\end{array}$ \\
\hline$[36]$ & $\mathrm{PA} 6,6$ & $12 \%$ in 3:1 FA:AA & $75-250$ & $1.6-2.0 \mathrm{~g} / \mathrm{m}^{2}$ & $\operatorname{PrP}$ & {$[0]_{20}$} & $\begin{array}{l}\text { Delamination onset life: improved } \\
\text { Fatigue } \mathrm{G}_{\mathrm{I}, \mathrm{C}}:+66 \%\end{array}$ \\
\hline$[39]$ & $\mathrm{PA}$ & $20 \%$ in 1:1 FA:CLF & $400-650$ & $40 \mu \mathrm{m}\left(1.8 \mathrm{~g} / \mathrm{m}^{2}\right)$ & $\operatorname{PrP}$ & {$[0 / 90]_{14}$} & $\mathrm{G}_{\mathrm{I}, \text { threshold }:+90 \%}$ \\
\hline$[45]$ & $\mathrm{PA} 6,6$ & $20 \%$ in 1:1 FA:CLF & $520 \pm 100$ & $18 \mathrm{~g} / \mathrm{m}^{2}$ & $\operatorname{PrP}$ & {$[0 / 90]_{14}$} & Fatigue life: $+96 \%$. \\
\hline
\end{tabular}

Table 4: Papers on Mode I/II Fatigue tests

Fatigue tests have been performed by cyclically loading samples according to the mode at a lower loading compared to that supposed to initiate delamination. All the fatigue tests reported in literature present a significant positive effect of the nanofibers on delamination grow rate, fatigue life, and delamination onset. Polymeric nanofibers are made of soft materials, compared with both the epoxy resin and the carbon/glass reinforcement, and when interleaved in low-stress samples like those under cyclic loads, can have an even higher impact compared to when interleaved in high-stressed 
static tested samples. An accurate and deep analysis of the micro- and nanomechanics inside an interleaved laminate during fatigue tests is presented in [31]. The three reinforce mechanisms mentioned above for the static tests can take place during a cyclic solicitation, together with some specific mechanisms, and in particular three regions with different behaviour have been observed. Interlaminar crossing is the behaviour observed in region 1, at the early stage of the test, and the delamination propagates slower than in non-interleaved material. In the next region 2 , during fracture propagation the interlaminar crossings gradually fades away, to eventually disappear in the region 3, where the delamination growth rate equals that of the noninterleaved material. Regions 2 and 3 are separated by a transition zone in which the interlaminar crossings combine and disappear.

\subsection{Tension}

The most straightforward characterisation test for the vast majority of materials is the tensile test: a beam-like sample is pulled apart from the two ends; the stress-strain behaviour recorded during the test provides a number of fundamental parameters: ultimate and yielding stresses and strains, Young's modulus, elastic field, and etc. . Composites do not make exception and papers have been found reporting results of tensile tests on nanomodified samples.

When a composite laminate is subjected to a tensile load, its components work in parallel: resin, fiber, and, when present, nanofibers, all act as parallel spring; consequently, fibers bear most of the load, as they are the stiffest and strongest component. Within this frame, polymeric, randomly oriented nanofibers would not be expected to give significant contribution; however several authors found otherwise, and their results are summarised in Table 5 .

The most used polymer is the PVA, and tests on carbon fibers present a very close range of results: [22] (PW laminates), [59] (UD laminates), and [60] (PW CF/VE composites), where 12, 9, and 11\% improvement in tensile strength have been reported, respectively. In [66] similar (UD and woven specimens, P(St-co-GMA) nanofibers) but only minor improvements have been found: their open holed specimens' tensile strength registered a tensile strength $5 \%$ higher than that of the control sample.

In [22] and [60], samples are tested under tensile-tensile fatigue loads, and present very similar improvements: nanomodified samples had 10 to 30 and 3 to 50 times longer lives, respectively. 
(a) Glass fibers - Papers on Static Tensile tests

\begin{tabular}{|c|c|c|c|c|c|c|c|}
\hline Ref \# & Pol & Solution & $\mathbf{N F}_{\text {diam }}$ & $\mathbf{N F}_{\text {amount }}$ & Man & Layup & Results \\
\hline$[30]$ & PA6 & $16 \%$ in $1: 1 \mathrm{FA}: \mathrm{AA}$ & $\begin{array}{l}150 \pm 19 \\
230 \pm 26\end{array}$ & $\begin{array}{l}5 \mathrm{~g} / \mathrm{m}^{2} \\
10 \mathrm{~g} / \mathrm{m}^{2}\end{array}$ & VARTM & {$[0,90]_{2 \mathrm{~s}}$} & $\begin{array}{l}\text { Stress at failure: }+6 \% \\
\text { Stress at failure: }+11 \%\end{array}$ \\
\hline$[32]$ & PA6,6 & $10 \%$ in $75: 25 \mathrm{FA}: \mathrm{CLF}$ & $110 \mathrm{~nm}$ & $0.525-1.05 \mathrm{~g} / \mathrm{m}^{2}$ & VARTM & {$[0]_{4}$} & Modulus/Strength: none/-10\% \\
\hline$[50]$ & PCL & $14 \%$ in $1: 1 \mathrm{FA}: \mathrm{AA}$ & $400 \pm 100$ & $\begin{array}{l}30-176 \mu \mathrm{m} \text { single layer } \\
17-89 \mu \mathrm{m} \text { double layer }\end{array}$ & VARTM & $\begin{array}{l}{[0]_{8}} \\
{[0,90]_{2 \mathrm{~s}}}\end{array}$ & Results not affected \\
\hline [69] & Silk & $13 \%$ in $\mathrm{FA}$ & $50-100$ & $0,3,5,10 \%$ ooresin content & VARTM & {$[0 / 90]_{10}$} & Strength: $+5 \%$ at $0.05 \%$ wt. \\
\hline
\end{tabular}

(b) Carbon fibers - Papers on Fatigue Tensile tests

\begin{tabular}{|c|c|c|c|c|c|c|c|}
\hline $\begin{array}{l}\text { Ref \# } \\
{[22]}\end{array}$ & $\begin{array}{l}\text { Pol } \\
\text { PVA }\end{array}$ & $\begin{array}{l}\text { Solution } \\
16,18,20,22 \% \text { in } \mathrm{H}_{2} \mathrm{O}\end{array}$ & $\begin{array}{l}\mathbf{N F}_{\text {diam }} \\
40-80\end{array}$ & $\begin{array}{l}\mathbf{N F}_{\text {amount }} \\
\text { mixed into epoxy }\end{array}$ & $\begin{array}{l}\text { Man } \\
\text { PrP }\end{array}$ & $\begin{array}{l}\text { Layup } \\
\mathrm{NA}\end{array}$ & $\begin{array}{l}\text { Results } \\
\text { Strength: }+5 \%\end{array}$ \\
\hline$[59]$ & PVA & $15 \%$ in $\mathrm{H}_{2} \mathrm{O}$ & $329 \pm 58$ & $7.10 \pm 0.70 \mathrm{~g} / \mathrm{m}^{2}$ & VARTM & {$[0]_{4}$} & Strength: $+12 \%$ \\
\hline$[60]$ & PVA & $20 \%$ in $\mathrm{H}_{2} \mathrm{O}$ & $80-100$ & $0.05-0.1$ wt. $\%$ & VARTM & {$[0]_{8}$} & $\begin{array}{l}\text { Strength: }+11 \% \\
\text { Young's modulus reduced } \\
\text { Strain at failure increased }\end{array}$ \\
\hline$[66]$ & $\mathrm{P}($ St-co-GMA) & $30 \%$ in $\mathrm{DMF}$ & $300-600$ & 5 interlayers & $\operatorname{PrP}$ & $\begin{array}{l}{[0]_{6}} \\
{[0 / 90]_{6}}\end{array}$ & $\begin{array}{l}\text { Strength: }+12 \% \\
\text { Strength: }+9-18 \%\end{array}$ \\
\hline
\end{tabular}

(c) Carbon fibers - Papers on Static Tensile tests

\begin{tabular}{|c|c|c|c|c|c|c|c|}
\hline $\begin{array}{l}\text { Ref \# } \\
{[22]}\end{array}$ & $\begin{array}{l}\text { Pol } \\
\text { PVA }\end{array}$ & $\begin{array}{l}\text { Solution } \\
16,18,20,22 \% \text { in } \mathrm{H}_{2} \mathrm{O}\end{array}$ & $\begin{array}{l}\mathbf{N F}_{\text {diam }} \\
40-80\end{array}$ & $\begin{array}{l}\mathbf{N F}_{\text {amount }} \\
\text { mixed into epoxy }\end{array}$ & $\begin{array}{l}\text { Man } \\
\text { PrP }\end{array}$ & $\begin{array}{l}\text { Layup } \\
\text { NA }\end{array}$ & $\begin{array}{l}\text { Results } \\
\text { Life: }+10-30 \text { times }\end{array}$ \\
\hline [60] & PVA & $20 \%$ in $\mathrm{H}_{2} \mathrm{O}$ & $80-100$ & $0.05-0.1$ wt. $\%$ & VARTM & {$[0]_{8}$} & Life: $+3-50$ times \\
\hline
\end{tabular}

Table 5: Papers on Tensile tests

Three works in literature have been found dealing with tensile properties of nanomodified GFRP laminates, and they do not show the same agreement registered for carbon fibers. In [50] it is showed that tensile properties of UD GFRP laminates are not affected by the presence of PCL nanofiber; in [30], it is shown that PA6 nanofibers caused an increase of stress at failure of the composite of about $6 \%$ and $11 \%$ when the nanofibers were added during layup and when directly deposited onto the fabric, respectively. A unique use of Silk has been presented in [69], showing a 5\% improved tensile strength. The main evidence of the reinforcing mechanisms of a nanointerleave in tensile tested specimens is provided in [113]. In particular it has been observed that Poisson's ratio mismatches and edge effects have a significant role on the delamination resistance of composite laminates subjected to static and fatigue tensile loads, and it is the field of action of the nanofibers. In [30] it is suggested that nanofibers prevent or minimize the formation of delamination cracks between two fiber plies, and also demonstrated that the nanofibers facilitate the load transfer from the resin to the glass fibers. They also agree with results showed in [60], on the fact that the nanolayers create a matrix-enriched interlayer, which extensive deformation and slower growth 
of damage improve the tensile properties of the laminate.

\subsection{Pure bending}

Interleaving a nanofibrous layer in between plies of a sample subjected to bending, follows the same base idea that has been presented in Section $§ 3.1$ on Mode II fracture mechanics. The only difference here is that the tested samples are not pre-cracked, and therefore the interply that will delaminate is not known a priori. In fact it is not even known if the sample fails for delamination of for matrix/fiber breakage.

Similar experiments, such as 3PB or 4PB [21, 24, 27, 28, 32, 33, 57, 59, 71, 72], ILSS [24, 32, 53, 77], and SBSh [21, 33, 78] have been performed to investigate behaviour of nanomodified composites under bending loads. Areas of interest are the flexural properties of the laminates and the shear stresses occurring between two laminae. Pure bending stress, like that generated with 4PB tests, usually breaks fibers on the tensile side of the specimens before inducing delamination; in ILSS and SBSh tests, instead, the load is applied to a very short beam to generate dominant shear stresses on the interlaminar region where the nanofibers are laid, increasing the chances of delamination. Three papers have been found testing glass fibers, and eight carbon fibers; results are shown in Table 6 .

Despite few works presenting negative results under certain conditions $[21,24,28]$, experiments generally show the positive effects that the interleave has on the composite laminates.

The reasons for such improvements are related to aspects discussed in Section 3.1.2, in particular to the matrix reinforcing effect. In [28] it is mentioned that nanofibers have the effect of reinforcing regions with localised stress concentrations, reducing stress concentration effects. In [27] it is claimed that nanofibers cause a delay in in-plane bending damage and thus delamination. An interesting point of view is presented in [24], where the beneficial effects of the nanofibers are attributed to their energy-absorption behaviour and to the fact that they transfer load toward the carbon fibers, again reducing stress concentrations.

\subsection{Impact}

In those applications where laminates are employed on outer sides of structures (e.g. airplanes, cars, etc.), impacts are a main concern, and the delamination behaviour of laminates subjected to impulsive loads has been 
(a) Glass fibers - Papers on Bending tests

\begin{tabular}{|c|c|c|c|c|c|c|c|}
\hline Ref \# & Pol & Solution & $\mathrm{NF}_{\text {diam }}$ & $\mathbf{N F}_{\text {amount }}$ & Man & Layup & Results \\
\hline$[21]$ & $\begin{array}{l}\text { PA6 } \\
\text { Epoxy } 609 \\
\text { TPU }\end{array}$ & $\begin{array}{l}10 \% \text { in } 3: 7 \text { FA:TFE } \\
29 \% \text { in } 3: 1 \text { MEK:PGME } \\
10 \% \text { in } 1: 1 \text { DMF:THF }\end{array}$ & $\begin{array}{l}150-500 \\
350-1200 \\
300-600\end{array}$ & $\begin{array}{l}20-150 \mu \mathrm{m} \\
\text { all interfaces interleaved }\end{array}$ & $\operatorname{PrP}$ & {$[0]_{8}$} & $\begin{array}{l}\text { Strength: }-30 \% \\
\text { Modulus: }+16 /-40 \% \\
\text { ILSS: }+18 /-50 \%\end{array}$ \\
\hline$[71]$ & TEOS & see reference & 200 & $\begin{array}{l}6 \mu \mathrm{m}\left(2.5 \mathrm{~g} / \mathrm{m}^{2}\right) \\
\text { all interfaces interleaved }\end{array}$ & VARTM & {$[0 / 90]_{6}$} & $\begin{array}{l}\text { Strength: }+65 \% \\
\text { Modulus: }+33 \% \\
\text { ILSS: }+105 \%\end{array}$ \\
\hline$[72]$ & TEOS & see reference & $250-450$ & $\begin{array}{l}1-2 \% \\
\text { half interfaces interleaved }\end{array}$ & VARTM & {$[0 / 90]_{8}$} & $\begin{array}{l}\text { Strength: }+14 \% \\
\text { Modulus: }+8 \% \\
\text { Energy absorption: }+93 \%\end{array}$ \\
\hline$[77]$ & TEOS & From Sol-Gel & $250-300$ & $0.2-0.8 \%$ wt. & VARTM & {$[0 / 90]_{4}$} & Strength: $+15 \%$ \\
\hline [78] & TEOS & From Sol-Gel & 250-300 & NA & $\operatorname{PrP}$ & $\begin{array}{l}{[0]_{12}} \\
{[0,90,90,0,0,90]_{\mathrm{s}}} \\
{[0,60,-60,-60,60,0]_{\mathrm{s}}} \\
{\left[(+45,-45)_{3}\right]_{\mathrm{s}}}\end{array}$ & $\begin{aligned} & +16 \% \\
\text { Energy absorbed: } & +7 \% \\
& +20 \% \\
& +4 \%\end{aligned}$ \\
\hline
\end{tabular}

(b) Carbon fibers - Papers on Bending tests

\begin{tabular}{|c|c|c|c|c|c|c|c|}
\hline Ref \# & PAN & $11 \%$ in DMF & $\begin{array}{l}\mathbf{N F}_{\text {diam }} \\
195 \pm 46\end{array}$ & $\begin{array}{l}\mathbf{N F} \text { amount } \\
27 \pm 5 \mu \mathrm{m} \\
\text { all interfaces interleaved }\end{array}$ & Man & $\begin{array}{l}\text { Layup } \\
{[0]_{6}} \\
{[0 / 90]_{4}} \\
{[0]_{3}} \\
{[0 / 90]_{4}}\end{array}$ & $\begin{array}{l}\text { Results } \\
\text { 3PB: Strength/Modulus: }+21 /+54 \% \\
\text { 3PB: Strength/Modulus: }-12 /+13 \% \\
\text { ILSS: }+11 \% \\
\text { ILSS: }+7 \%\end{array}$ \\
\hline [27] & PAN & $5 \%$ in DMF & 150 & all interfaces interleaved & $\operatorname{PrP}$ & {$[0 / 90]_{8}$} & $\begin{array}{l}\text { Modulus: }+21 \% \\
\text { Strength: }+56 \%\end{array}$ \\
\hline [28] & $\begin{array}{l}\text { PCL } \\
\text { PVDF } \\
\text { PAN }\end{array}$ & $\begin{array}{l}12-15-20 \% \text { in } 1: 1 \text { DMF:CHL } \\
16 \% \text { in } 1: 1 \text { DMF:AC } \\
13 \% \text { in DMF }\end{array}$ & $\begin{array}{l}103-125-210 \\
542 \\
607\end{array}$ & $0.2 \%$ & VARTM & {$[0 / 90]_{4}$} & Modulus: $-19 \%$ \\
\hline [32] & PA6,6 & $10 \%$ in $75: 25 \mathrm{FA}: \mathrm{CLF}$ & $110 \mathrm{~nm}$ & $0.525-1.05 \mathrm{~g} / \mathrm{m}^{2}$ & VARTM & {$[0]_{4}$} & $\begin{array}{l}\text { Modulus/Strength: }+16 \% /+13 \% \\
\text { ILSS: }+10 \%\end{array}$ \\
\hline [33] & PA6,6 & $14 \%$ in $1: 1 \mathrm{FA}: \mathrm{CLF}$ & $170 \pm 30$ & $\begin{array}{l}30 \mu \mathrm{m} \\
1 \text { and } 9 \text { interlayers }\end{array}$ & $\operatorname{PrP}$ & {$[0]_{10}$} & $\begin{array}{l}\text { 3PB: Modulus not affected } \\
\text { ILSS: }+32 \%\end{array}$ \\
\hline [42] & PA6,6 & $14 \%$ in 1:1 FA:CLF & $150 \pm 20$ & $\begin{array}{l}25 \pm 8 \mu \mathrm{m} \\
2 \text { interfaces per side, symmetric } \\
3 \text { interfaces, bottom side }\end{array}$ & $\operatorname{PrP}$ & {$[0 / 90]_{10}$} & $\begin{array}{l}\text { Stiff before impact: }-12 \% \\
\text { Stiff after impact: }+7 \%\end{array}$ \\
\hline [53] & Phenoxy & $30 \%$ in 3:7 DMF:THF & $909 \pm 126$ & $70 \mu \mathrm{m}$ - all interfaces interleaved & PrP & {$[0 / 90]_{8}$} & ILSS unchanged \\
\hline$[57]$ & PSF & $25 \%$ in 9:1 DMAC:AC & 230 & $1 \%, 3 \%, 5 \%$ of resin matrix & $\operatorname{PrP}$ & {$[0]_{24}$} & $\begin{array}{l}\text { Strength: }+5 \% \\
\text { Modulus unchanged }\end{array}$ \\
\hline [59] & PVA & $15 \%$ in $\mathrm{H}_{2} \mathrm{O}$ & $329 \pm 58$ & $7.10 \pm 0.70 \mathrm{~g} / \mathrm{m}^{2}$ & VARTM & {$[0]_{4}$} & $\begin{array}{l}\text { Modulus: }+21 \% \\
\text { Strength: }+16 \% \\
\end{array}$ \\
\hline
\end{tabular}

Table 6: Papers on Bending tests

widely investigated. Impacts on composite structures may induce delamination cones through the thickness, irreversibly damaging the structure [114]. Depending on the severity of the impact, such cone can develop from top to the bottom of the laminate $(\bigvee$ shape), or from the bottom to the top $(\bigwedge$ shape). Interleaving nanofibers into specimens subjected to impacts has the purpose of hindering the formation and the development of such cone. Table 7 summarise the literature on this specific type of load. 
(a) Glass fibers - Papers on Impact tests

\begin{tabular}{|c|c|c|c|c|c|c|c|}
\hline $\begin{array}{l}\text { Ref \# } \\
{[29]}\end{array}$ & $\begin{array}{l}\text { Pol } \\
\text { PCL } \\
\text { PA6 }\end{array}$ & $\begin{array}{l}\text { Solution } \\
12 \% \text { in } 9: 1 \mathrm{FA}: \mathrm{AA} \\
16 \% \text { in 1:1 FA:AA }\end{array}$ & $\begin{array}{l}\mathbf{N F}_{\text {diam }} \\
343 \pm 150 \\
195 \pm 35\end{array}$ & $\begin{array}{l}\mathbf{N F}_{\text {amount }} \\
5-15 \mathrm{~g} / \mathrm{m}^{2} \\
4-20 \mathrm{~g} / \mathrm{m}^{2} \text { - all interfaces interleaved }\end{array}$ & VARTM & {$[0 / 90]_{2 \mathrm{~s}}$} & Damaged area: $-50 \%$ \\
\hline [49] & PA6,9 & $20 \%$ in $1: 1 \mathrm{FA}: \mathrm{AA}$ & $\begin{array}{l}457 \pm 53 \text { random } \\
464 \pm 110 \text { aligned }\end{array}$ & $\begin{array}{l}11 \pm 0.5 \mathrm{~g} / \mathrm{m}^{2} \\
1 \text { interlayer }\end{array}$ & PrP & {$[0]_{12}$} & Mode II IFT: $+50-100 \%$ \\
\hline [51] & PCL & $12 \%$ in $3: 2$ FA:AA & 300 & $30 \mu \mathrm{m}$ all interfaces interleaved & $\operatorname{PrP}$ & {$[0,90,0,90]_{\mathrm{s}}$} & Damaged area: $-26 \%$ \\
\hline [64] & PVDF & 15\% in 3:7 DMSO:AC & $300-700$ & $39,64 \mu \mathrm{m}$ - all interfaces interleaved & $\operatorname{PrP}$ & {$[0,90,0,90]_{\mathrm{s}}$} & Absorbed energy: $+10-13 \%$ \\
\hline [71] & TEOS & see reference & 200 & 6 with $2.5 \mathrm{~g} / \mathrm{m}^{2}$ - all interfaces interleaved & VARTM & {$[0 / 90]_{6}$} & Absorbed energy: $+37 \%$ \\
\hline [75] & TEOS & From Sol-Gel & & $8.2 \mathrm{~g} / \mathrm{m}^{2}-$ all interfaces interleaved & $\operatorname{PrP}$ & {$[0 / 90]_{10}$} & Damaged area: $+9 \%$ \\
\hline
\end{tabular}

(b) Carbon fibers - Papers on Impact tests

\begin{tabular}{|c|c|c|c|c|c|c|c|}
\hline $\begin{array}{l}\text { Ref \# } \\
{[24]}\end{array}$ & PAN & $11 \%$ in $\mathrm{DMF}$ & $\begin{array}{l}\mathbf{N F}_{\text {diam }} \\
195 \pm 46\end{array}$ & $\begin{array}{l}\mathbf{N F} \text { amount } \\
27 \pm 5 \mu \mathrm{m} \\
\text { all interfaces interleaved }\end{array}$ & HLu & $\begin{array}{l}\text { Layup } \\
{[0]_{6}} \\
{[0 / 90]_{4}} \\
{[0 / 90]_{4}}\end{array}$ & $\begin{array}{l}\text { Results } \\
\text { Absorbed energy: }+64 \% \\
\text { Increase in initiation/total } \\
\text { breaking energies }\end{array}$ \\
\hline [32] & PA6,6 & $10 \%$ in $75: 25 \mathrm{FA}: \mathrm{CLF}$ & $110 \mathrm{~nm}$ & $0.525-1.05 \mathrm{~g} / \mathrm{m}^{2}$ & $\operatorname{PrP}$ & {$[0]_{4}$} & Strength: $+18 \%$ \\
\hline$[34,36]$ & PA 6,6 & $12 \%$ in $3: 1 \mathrm{FA}: \mathrm{AA}$ & $75-250$ & $\begin{array}{l}1.7 \mathrm{~g} / \mathrm{m}^{2} \\
\text { all interfaces interleaved }\end{array}$ & $\operatorname{PrP}$ & {$[-45,90,45,0]_{2 \mathrm{~s}}$} & $\begin{array}{l}\text { Damage: }-33 \% \\
\text { Threshold force: }+60 \% \\
\text { Damage growth rate: }-50 \%\end{array}$ \\
\hline [40] & PA6, 6 & $10 \%$ in $3: 1 \mathrm{FA}: \mathrm{AA}$ & $65-120$ & $\begin{array}{l}0.7 \mathrm{~g} / \mathrm{m}^{2} \\
\text { all interfaces interleaved }\end{array}$ & $\operatorname{PrP}$ & {$[-45,90,45,0]_{3 \mathrm{~s}}$} & $\begin{array}{l}\text { Delamination on-set force: }+7 \% \\
\text { Threshold energy }+33 \%\end{array}$ \\
\hline [42] & PA 6,6 & $14 \%$ in $1: 1 \mathrm{FA}: \mathrm{CFL}$ & $150 \pm 20$ & $\begin{array}{l}25 \pm 8 \mu \mathrm{m} \\
2 \text { interfaces per side, symmetric } \\
3 \text { interfaces, bottom side }\end{array}$ & $\operatorname{PrP}$ & {$[0 / 90]_{10}$} & $\begin{array}{l}\text { Peak force: }-8 \% \\
\text { Energy absorption: }-14 \%\end{array}$ \\
\hline [59] & PVA & $15 \%$ in $\mathrm{H}_{2} \mathrm{O}$ & $329 \pm 58$ & $\begin{array}{l}7.10 \pm 0.70 \mathrm{~g} / \mathrm{m}^{2} \\
\text { all interfaces interleaved }\end{array}$ & VARTM & {$[0]_{4}$} & Fracture energy: $+11 \%$ \\
\hline$[67]^{*}$ & $\mathrm{P}($ St-co-GMA) & $30 \%$ in DMTF & 400 & $0.1 \%$ wt. & $\operatorname{PrP}$ & {$[0 / 90]_{25 \mathrm{~s}}$} & $\begin{array}{l}\text { Energy dissipation }+80 \% \text { in-plane, } \\
+40 \% \text { through thickness }\end{array}$ \\
\hline
\end{tabular}

* Compressive Split-Hopkinson pressure bar test

Table 7: Papers on Impact tests

The effects of nanointerleave on CFRP subjected to LVI have been mainly investigated using PA6, 6 nanofibers as reinforce [34, 36, 40, 42]. In [34, 36, 40] UD samples interleaved at each interface have been tested, while [42] tested woven laminates with nanofibers only in selected interlayers. An important parameter in impacts is the sample's thickness: in [34, 36] nanofibers increased sample's thickness of $1-2 \%$, while in $[40,42]$ pristine and nanomodified samples had the same thickness, due o a lower number of interleaves. The most common impact test is the LVI test, where a spherical object is dropped falling from a certain height to the specimens [34, 36, 40, 42]. These papers all present very positive results in terms of improved impact threshold force $(+64 \%)$, damaged area $(-50 \%)$, damage resistance (3 times), delamination on-set force $(+7 \%)$, threshold energy $(+33 \%)$, peak force $(-8 \%)$ and energy absorbed during the event $(-14 \%)$ in nanomodified laminates compared to virgin ones.

A different type of impact is given in the Charpy test, used in [24] and [59]. Those tests have been conducted at different energy levels: the Charpy pendulum had speed of 2.9 and $3.46 \mathrm{~m} / \mathrm{s}$, and energy of 2 and 15J in [24] 
and [59], respectively. Results show a reduction of the effectiveness of the nanoreinforce at high values of energy: nanofibers are still effective after a 15J impact, but the improvement falls from $64 \%$ to $11 \%$, moving from $2 \mathrm{~J}$ impacts. Similar conclusions have been drown in [42], where specimens are tested under LVI protocol.

Glass fibers received even more attention than carbon, and among the papers here considered, only one showed negative results [75].

In [64] and [51], plain and curved glass-fiber specimens have been tested, respectively, showing positive results in terms of absorbed energy $(+9,5 \%$ and $+13,4 \%$, depending on the thickness of the nanomat) and damaged area $(-27 \%)$.

In $[29,49]$, the same authors present interesting studies using different types of nanofibers and different nanofiber orientation. In [29] authors used PCL and PA: PA showed negligible effect, while PCL nanofibers reduced the damaged area down to $50 \%$. It is also observed that when nanofibers are oriented parallel to the crack growth direction, the main reinforce mechanism is the matrix strengthening; laminates interleaved with nanofibers oriented transversely to the crack growth direction showed nanofiber bridging, making this orientation more effective than the other. Laminates interleaved with a random deposition of nanofibers resulted in the largest increase in Mode II IFT, due to the contribution of both types of reinforcement.

An interesting work has been presented in [71], where electrospun glass fibers are used to manufacture a multi-scale three-phase composite laminate with $37 \%$ higher impact energy compared to the control sample.

The SEM images shown in [42], revealed that after impacts several nanofibers still link the two layers they are inserted in between, suggesting a strong fiber bridging effect. The best insights on reinforcing mechanisms are presented in $[29,49]$, where two types of failure have been identified: interlaminar failure and intralaminar crossing. The authors assessed that depending on their orientation, nanofibers act independently on the two types of failures. Their multiscale investigation confirms the nanofibers bridging mechanism as main reinforcing effect during impacts.

\subsection{Compression after Impact}

As mentioned before, nanofibers interleaved in specimens subjected to impacts aims to be beneficial by reducing the formation of the delamination cone; at the same time, due the smaller delamination cone, and the presence of intact nanofibers, result in better sample's residual properties.. 
Literature presents only two papers on the residual compression properties of composites after impacts, and the results are summarised in Table 8.

(a) Glass fibers - Papers on CAI tests

\begin{tabular}{llllllll}
\hline Ref \# & Pol & Solution & $\mathbf{N F}_{\text {diam }}$ & $\mathbf{N F}_{\text {amount }}$ & Man & Layup & Results \\
{$[76]$} & TEOS & TEOS:ethanol: $\mathrm{H}_{2} \mathrm{O}: \mathrm{HCl}$ 1:2:2:0.01 & NA & all interfaces interleaved & PrP & NA & Residual strength: $-29 \%$ \\
\hline
\end{tabular}

(b) Carbon fibers - Papers on CAI tests

\begin{tabular}{llllllll}
\hline Ref \# & Pol & Solution & $\mathbf{N F}_{\text {diam }}$ & $\mathbf{N F}_{\text {amount }}$ & Man & Layup & Results \\
{$[40]$} & PA6,6 & $10 \%$ in 3:1 FA:AA & $65-120$ & $0.7 \mathrm{~g} / \mathrm{m}^{2}$ - all interfaces interleaved & PrP & {$[-45,90,45,0]_{3 \mathrm{~s}}$} & Strength: $+10 \%$ \\
\hline
\end{tabular}

Table 8: Papers on CAI tests

In [40] PA6,6 nanofibers are interleaved into laminates, and it is found that the compression strength after impact increased of about 10\%. Similarly to what found in [42], authors observed that the compression residual strength ratio between the nanomodified and the virgin samples decreases at increasing impact energy.

The negative results reported in [76] will be discussed in $\S 4$.

\subsection{Vibration}

The study of vibrational behaviour of composites is of great importance, especially for delamination evaluation and non-destructive structural health monitoring techniques [115-117]. Despite the literature presents a large number of papers studying vibrations of composites, Table 9 shows that only two papers investigated vibrations of nanomodified laminates.

\begin{tabular}{|c|c|c|c|c|c|c|c|}
\hline Ref \# & Pol & Solution & $\mathbf{N F}_{\text {diam }}$ & $\mathbf{N F}_{\text {amount }}$ & Man & Layup & Results \\
\hline [42] & PA6,6 & $14 \%$ in $1: 1 \mathrm{FA}: \mathrm{CLF}$ & $150 \pm 20$ & $\begin{array}{l}25 \pm 8 \mu \mathrm{m} \\
4 \text { interfaces, symmetric } \\
3 \text { interfaces, bottom side }\end{array}$ & PrP & {$[0 / 90]_{10}$} & $\begin{array}{l}\text { Damping: }+250 \% \\
1^{\text {st }} \text { harmonic: }-17 \%\end{array}$ \\
\hline [47] & PA6,6 & $14 \%$ in $1: 1 \mathrm{FA}: \mathrm{CLF}$ & $150-250$ & $28.5 \mathrm{~g} / \mathrm{m}^{2}$ & $\operatorname{PrP}$ & {$[0,90,0,90,0]_{\mathrm{s}}$} & Damping: $+36 \%$ \\
\hline
\end{tabular}

Table 9: Papers on Vibration tests

In [42] bump tests are performed on carbon fiber specimens before and after three different energy level impacts; authors measured harmonic frequencies and damping of the samples before and after the event. Damping behaves as expected, with nanomodified samples showing higher damping due to resin-nanofiber friction during vibration, with the effect of the nanointerleave fading away as the impact energy increases. Harmonic frequencies instead showed an unexpected behaviour: the nanomodified specimens exhibit a self-strengthening effect after impacts. Pre-impact results show that 
nanomodified specimens are more compliant than their virgin counterparts due to the presence of ductile interlayers; once the matrix is broken, the nanofibers act as a bridge between the two plies, self-strengthening and selfrepairing the laminates.

Authors in [47] tested curved glass specimens with similar bump test, and found agreement with the other paper, showing an increased damping ratio.

\subsection{Nanofibers doped with CNT}

A selection of works testing polymeric electrospun nanofibers doped with carbon nanostructures such as $\mathrm{CNT}$ or $\mathrm{CNF}$ is here presented. $\mathrm{CNF} / \mathrm{CNT}$ are added into the polymeric solutions and electrospun together with the nanofibers, after a dedicated sonication process with the purpose of homogenising the solution. An interesting reading on how these are produced and employed can be found in [118-120].

CNT is the structure that has been the most employed in a range of different electropsun nanofibers.In [121] the effect of adding MWCNT has been assessed performed testing $\mathrm{P}$ (St-co-GMA) copolymer and P(St-co-GMA)/MWCNT nanofibrous mats interleaved into carbon fiber prepregs, and comparing the results. The authors performed flexural, ENF and Charpy-impact tests do determine the effect of adding MWCNT to the P(St-co-GMA) nanofibers. The improvements that the carbon nanoaddiction provides to the laminate is impressive, compared to its amount: flexural strength and stiffness increase up to 25 and $29 \%$, respectively, $\mathrm{G}_{\text {II,C }}$ up to $70 \%$, impact energy absorbance up to $20 \%$ and transverse tensile strength up to $27 \%$. The weight of the interleaved was $0.2 \%$ of that of the total laminate, and the MWCNT accounted for only $1 \%$ of it. Authors analysed cross sectional fracture surfaces, and attributed as the reason for such improvements to the high compatibility of the interlayers with the surrounding matrix. Double-digit improvements have been registered by almost any experimental studies performed on carbon-doped nanofibers. In $[122,123]$ CNTs are added into PU nanofibers, and interleaved into epoxy-basal composite, registering $13 \%$ increase in tensile and $17.3 \%$ in flexural strength compared to neat material, addressing the improvements to an enhanced fiber-resin adhesion. In [124] CNTs are added into PA nanofibers and embedded into pure resin: resin with $3 \%$ of MWCNT-PA nanofibers (in which the CNT accounted for the $1 \%$ in mass) led to improvements of modulus of elasticity, elongation at break and tensile strength of 690, 51 and 239\%, respectively. Authors addressed the improvements to the uniform distribution, alignment states and well interfacial 
adhesion between the nanofibers, the MWNTs and the epoxy matrix, the PA6 serves as an intermediate layer and alleviates the modulus mismatch between the stiff MWNTs and the softer epoxy matrix. In [125], 5\% and $10 \%$ CNTs/PSF interlayer has been interleaved info CFRP to investigate the mode I and mode II interlaminar toughness. $\mathrm{G}_{\mathrm{I}, \mathrm{C}}$ improved 41 and $53 \%$ with $5 \%$ and $10 \% \mathrm{CNTs} / \mathrm{PSF}$ content, respectively, due to the intense deformation of the epoxy matrix promoted by the PSF micro-particles and pull-out of CNTs; similarly, GII,C increased 25 and 34\%, respectively, due to better compatibility between epoxy and PSF. Flexural properties also improved: with $10 \% \mathrm{CNTs} / \mathrm{PSF}$ interleafs, flexural strength and flexural modulus improved of 27 and $29 \%$ compared to the control samples, respectively, owing to the reinforcing effect of the CNTs, simultaneously improving the interlaminar toughness and in-plane properties of the composite laminates.

\section{Reduced properties}

As shown in the previous sections, it is a general agreement that the nanofibers, under most conditions, are a powerful and effective reinforcement against delamination. However, few papers show a reduction of laminate's properties, and the aim of this section is to speculate what the causes might be:

- in $[20,21,23,44]$ it is shown that mechanical properties of nanomodified samples drop when the nanolayer reaches a certain thickness. It is observed that there is a threshold value on the amount of nanoreinforce after which the compliance of a randomly aligned polymeric nanofibrous mat overcomes the strengthening effect of the same;

- in [28], PAN, PCL and PVDF are used to produce nanofibers, and only PCL provided good results. Authors highlighted the need for a correct polymerisation-induced phase separation. The high viscosity of the polymer may retain the diffusion of the matrix though the nanofibers during the curing process, making the choice of the polymer a critical aspect with regard of the resin. The importance of the nanofibers-composite interaction is also presented in [35], where significantly different results have been found when interleaving the same nanofibers into different laminates; 
- in [38], it is shown that also the load plays an important role when addressing the effectiveness of the nanoreinforce. Authors registered a significant slower crack propagation under Mode II loading than under Mode I due to the fiber direction. It is demonstrated that under Mode I, the loading of the nanofibers is less optimal and dependent on both the fabric architecture of the primary reinforcement, and on the presence of a carbon fiber bridging zone. Similar results have been found in $[59,61,73]$ where different outcomes have been registered between Mode I and Mode II tests on the same samples. ENF nanomodified specimens registered improved properties compared to the neat configuration, while DCB specimens did the opposite. In [73], it is speculated that it may be attributed to improper wetting compaction;

- in $[75,76]$ it is shown that TEOS-nanomodified impacted specimens have larger delamination that the pristine ones, with lower strength after impact. It can be noted that other works using the same nanofibers [71-73] registered improvements when a comparable amount of nanofiber is interleaved. The detriment found in [75, 76] may be attributed to the fact that these last authors manufactured composites in autoclave, using prepreg, while those that registered improved properties manufactured samples using VARTM moulding. It is a subject that would require a deeper investigation, but these results lead to the idea that VARTM process may result in better resin penetration through the nanofibers, while the prepreg is more prone to create voids that weaken the interface if the nanomat is not porous enough;

- in [93] the propagation fracture energy has been found to be slightly lower in the interleaved samples compared to the non-interleaved ones. This has been attributed to the fact that woven fabrics introduces several in-homogeneities at the meso-scale that may favour the onset of a stick-slip propagation behaviour and the formation of thick carbon fiber bridges in the wake of the delamination.

\section{Lack of research}

The research on electrospun nanofibers for reinforcing purposes started several years ago, a large number of papers has been published, and a solid knowledge has been built on the topic since then. Nevertheless, the path for a full understanding of the mechanisms that rule the behaviour of the 
nanoreinforce has still to be completed. Despite nanofibers have already found application in various fields, their wide introduction in laminates for reinforcing purposes has still a long way to go. Among the issues that still need to be solved (costs, dangerous chemicals, low production rate, strong dependence from environment, slow lay-up, full compatibility with the resin, low repeatability of the interleaved composite, ...), this section focuses on the gaps that still need to be filled from a research point of view, in terms of understanding the behaviour of nanomodified composite.

As shown in the tables presented in Section 3, fracture mechanics is largely the most common approach for investigating nanomodified composites, due to the interest in evaluating the fracture propagation, related to the delamination behaviour of the laminates, and thus to their most common failure mode. However, this review shows that there are still few poorly investigated aspects:

- Mode I testing has covered almost all the main aspects; however, fatigue behaviour and fracture propagation under static load in GFRP still need to be fully addressed and investigated;

- Mode II testing, instead, has still several gaps mainly due to the difficult task of addressing crack propagation in the sliding mode. For this reason, data on fatigue behaviour and $\mathrm{G}_{\mathrm{II}, \mathrm{R}}$ for both GFRP and CFRP is almost absent.

Research on impact behaviour of nanomodified samples is affected by the large number of variables that has to be taken into account (thickness, layup, energy and speed of the impactor, number of nanolayers, ...), and it is still far to be completed. From the outcome of this review, there is still very little known about an optimal strategy to effectively interleave a laminate and strengthen its resistance to impacts. Samples for impact tests are usually larger than those used for the other tests, and require a significantly greater amount of nanofibers (i.e. for Mode I and Mode II samples only the delaminated interface is interleaved), because several (if not all) interfaces are nanomodified, making the research expensive in terms of resources and time.

The field of research that is still at its beginning is that on vibrations: only two papers have been found investigating vibrational behaviour of nanomodified composites. A very important aspect is the effect of the nanointerleave 
on the damping of the structure it is interleaved in, which will have important application and implication for those structures which free vibration are source of problems. If nanofibers are proved to be able to reduce, or tune, reliably, the free vibration response of a structure, it will give a significant impulse to their application in industry.

One of the main bottleneck to a greater diffusion of nanofibers in industry is its slow production rate $[16,126]$. Despite several companies around the world are producing machines for electrospinning, the technology is not mature enough to be introduced in a production line, at least for the vast majority of the manufacturer. A research effort on improving manufacturing techniques, focusing on reducing the time, would significantly benefit and encourage the use of nanofibers in a larger number of applications.

\section{Conclusions}

In this review the state-of-the art of composite laminates interleaved with electrospun nanofibers for reinforcing purposes has been introduced and analysed.

The papers found in literature have been presented with a mechanical approach, focusing on the main types of load an object can be solicited with. Case by case, the effect of the nanofibers and their working mechanism has been deeply investigated by many researchers, and this review has summarised the main and most significant outcomes. The vast majority of the results shows that a nanofibrous interlayer between plies of a laminate can bring significant benefits from structural and load bearing points of view. Nanofibers' impact on a laminate is minimum, if not negligible, in terms of increase of weight and sizes, but the interleaved laminate's mechanical properties are significantly improved compared with that of the base material.

The research on this topic is certainly not over, as there are several issues still to be addressed, but nanofibers have the potential that makes the investigation worthwhile. When the technology will improve the few weak points still to be addressed, it is believed that nanomodified composites will have massive diffusion in the industry and in a wide range of products and application.

\section{Acknowledgement}

The authors would like to thank Mr. Francesco Diamantini for his precious help in bibliographic research. 


\section{References}

[1] A. A. Baker, R. Jones, R. J. Callinan, Damage tolerance of graphite/epoxy composites, Composite Structures 4 (1) (1985) 15-44. doi:10.1016/0263-8223(85)90018-2.

[2] T. O'Brien, Towards a Delamination Fatigue Methodology for Composite Materials, in: 16th International Conference on Composite Materials, Kyoto, 2007, pp. 1-5.

[3] S. Sridharan, Delamination behaviour of composites, CRC Press, 2008.

[4] G. Minak, R. Palazzetti, I. Trendafilova, A. Zucchelli, Localization of a delamination and estimation of its length in a composite laminate beam by the VSHM and pattern recognition methods, Mechanics of Composite Materials 46 (4) (2010) 387-394. doi: 10.1007/s11029-010-9155-9.

[5] W. Morton, Method of Dispersing Fluids (1902).

[6] J. Cooley, Apparatus for electrically dispersing fluids (1900).

URL http://www.google.com/patents/US692631

[7] R. Gopal, S. Kaur, Z. Ma, C. Chan, S. Ramakrishna, T. Matsuura, Electrospun nanofibrous filtration membrane, Journal of Membrane Science 281 (1-2) (2006) 581-586. doi:10.1016/j.memsci.2006.04.026. URL http://linkinghub.elsevier.com/retrieve/pii/S0376738806002651

[8] T. Subbiah, G. Bhat, R. Tock, S. Parameswaran, S. Ramkumar, Electrospinning of Nanofibers, Journal of Applied Polymer Science 96 (2) (2004) 557-569. doi:10.1002/app. 21481.

URL http://doi.wiley.com/10.1002/app.21481

[9] Y. Luu, K. Kim, B. Hsiao, B. Chu, M. Hadjiargyrou, Development of a nanostructured DNA delivery scaffold via electrospinning of PLGA and PLA-PEG block copolymers, Journal of Controlled Release 89 (2003) 341-353.

[10] D. Liang, B. Hsiao, B. Chu, Functional electrospun nanofibrous scaffolds for biomedical applications, Advanced drug delivery reviews 
59 (14) (2007) 1392-412. doi:10.1016/j.addr.2007.04.021.

URL http://www.pubmedcentral.nih.gov/articlerender.fcgi? artid $=2693708\{\&\}$ tool=pmcentrez $\{\&\}$ rendertype=abstract

[11] Y. Dzenis, D. Reneker, Delamination resistant composite prepared by small diameter fiber reinforcement at ply interfaces (1999).

[12] K. Shivakumar, R. Panduranga, Interleaved polymer matrix composites - A review, Collection of Technical Papers AIAA/ASME/ASCE/AHS/ASC Structures, Structural Dynamics and Materials Conferencedoi:10.2514/6.2013-1903.

URL http://www.scopus.com/inward/record.url?eid= 2-s2.0-84881364474\{\&\}partnerID=tZOtx3y1

[13] Z. Huang, Y. Zhang, M. Kotaki, S. Ramakrishna, A review on polymer nanofibers by electrospinning and their applications in nanocomposites, Composites Science and Technology 63 (15) (2003) 2223-2253. doi : 10.1016/S0266-3538(03)00178-7. URL http://linkinghub.elsevier.com/retrieve/pii/S0266353803001787

[14] A. Zucchelli, M. Focarete, C. Gualandi, S. Ramakrishna, Electrospun nanofibers for enhancing structural performance of composite materials, Polymers for Advanced Technologies 22 (3) (2011) 339-349. doi:10.1002/pat. 1837.

[15] X. Wang, Y. Zhao, H. Wang, G. Cai, Electric Field and Spinning Performance in Needleless Electrospinning, Advanced Materials Research 1048 (2014) 26-30. doi:10.4028/www. scientific.net/AMR . 1048. 26.

[16] F. Zhou, R. Hua, I. Porat, Needle and Needleless Electrospinning for Nanofibers, Journal of Applied Polymer Science 115 (5) (2010) 25912598. arXiv:1206.4529, doi:10.1002/app.

[17] S. Ramakrishna, An introduction to electrospinning and nanofibers, World Scientific, Singapore, 2005.

[18] G. Cicala, A. Latteri, S. Mannino, G. Ognibene, I. Blanco, Influence of Soluble Electrospun Co-Polyethersulfone Veils on Dynamic Mechanical and Morphological Properties of Epoxy Composites: Effect of Polymer Molar Mass, Advances in Polymer Technologydoi: 10.1002/adv. 21723. 
[19] L. Liu, Z. Huang, G. Xu, Y. Liang, G. Dong, Mode II Interlaminar Delamination of Composite Laminates Incorporating With Polymer Ultrathin Fibers, Polymer Composites 03 (2008) 285-292. doi: $10.1002 / \mathrm{pc}$.

[20] L. Liu, Y. Liang, G. Xu, H. Zhang, Z. Huang, Mode I Interlaminar Fracture of Composite Laminates Incorporating with Ultrathin Fibrous Sheets, Journal of Reinforced Plastics and Composites 27 (11) (2008) 1147-1162. doi:10.1177/0731684407086504.

[21] L. Liu, Z. Huang, C. He, X. Han, Mechanical performance of laminated composites incorporated with nanofibrous membranes, Materials Science and Engineering A 435-436 (2006) 309-317. doi: $10.1016 / j$.msea.2006.07.064.

[22] N. Phong, M. Gabr, K. Okubo, B. Chuong, T. Fujii, Improvement in the mechanical performances of carbon fiber/epoxy composite with addition of nano-(Polyvinyl alcohol) fibers, Composite Structures 99 (2013) 380-387. doi:10.1016/j. compstruct.2012.12.018.

[23] G. Beckermann, K. Pickering, Mode I and Mode II interlaminar fracture toughness of composite laminates interleaved with electrospun nanofibre veils, Composites Part A: Applied Science and Manufacturing 72 (2015) 11-21. doi:10.1016/j. compositesa.2015.01.028. URL http://dx.doi.org/10.1016/j.compositesa. 2015.01.028

[24] K. Molnar, E. Košt'áková, L. Mészáros, The effect of needleless electrospun nanofibrous interleaves on mechanical properties of carbon fabrics/epoxy laminates, Express Polymer Letters 8 (1) (2014) 62-72. doi:10.3144/expresspolymlett.2014.8.

[25] X. Wu, A. Rahman, Z. Zhou, D. Pelot, S. Sinha-Ray, B. Chen, S. Payne, A. Yarin, Electrospinning core-shell nanofibers for interfacial toughening and self-healing of carbon-fiber/epoxy composites, Journal of Applied Polymer Science 129 (3) (2013) 1383-1393. doi: 10.1002/app. 38838.

[26] S. Lomov, K. Molnar, Compressibility of carbon fabrics with needleless electrospun PAN nanofibrous interleaves, Express Polymer Letters 10 (1) (2016) 25-35. doi:10.3144/expresspolymlett.2016.4. 
[27] J. Herwan, E. Al-Bahkali, K. Khalil, M. Souli, Load bearing enhancement of pin joined composite laminates using electrospun polyacrylonitrile nanofiber mats, Arabian Journal of Chemistry 9 (2) (2016) 262-268. doi:10.1016/j.arabjc.2015.03.019.

URL http://dx.doi.org/10.1016/j.arabjc.2015.03.019

[28] J. Zhang, T. Yang, T. Lin, C. Wang, Phase morphology of nanofibre interlayers: Critical factor for toughening carbon/epoxy composites, Composites Science and Technology 72 (2) (2012) 256-262. doi:10.1016/j.compscitech.2011.11.010. URL http://dx.doi.org/10.1016/j.compscitech.2011.11.010

[29] L. Daelemans, S. van der Heijden, I. De Baere, H. Rahier, W. Van Paepegem, K. De Clerck, Damage resistant composites using electrospun nanofibers: a multiscale analysis of the toughening mechanisms., ACS Applied Materials \& Interfaces 8 (18) (2016) 11806-11818. doi:10.1021/acsami.6b02247.

URL http://dx.doi.org/10.1021/acsami.6b02247

[30] B. De Schoenmaker, S. Van Der Heijden, I. De Baere, W. Van Paepegem, K. De Clerck, Effect of electrospun polyamide 6 nanofibres on the mechanical properties of a glass fibre/epoxy composite, Polymer Testing 32 (8) (2013) 1495-1501. doi: 10.1016/j . polymertesting. 2013.09.015.

[31] L. Daelemans, S. van der Heijden, I. De Baere, H. Rahier, W. Van Paepegem, K. De Clerck, Improved fatigue delamination behaviour of composite laminates with electrospun thermoplastic nanofibrous interleaves using the Central Cut-Ply method, Composites Part A: Applied Science and Manufacturing 94 (2017) 10-20. doi: 10.1016/j.compositesa.2016.12.004.

[32] B. Beylergil, E. Aktas, M. Tano, Enhancement of interlaminar fracture toughness of carbon fiber epoxy composites using polyamide- 6,6 electrospun nanofibers, Journal of Applied Polymer Science 45244 (2017) 1-12. doi:10.1002/app. 45244.

[33] M. Di Filippo, S. Alessi, G. Pitarresi, M. Sabatino, A. Zucchelli, C. Dispenza, Hydrothermal aging of carbon reinforced 
epoxy laminates with nanofibrous mats as toughening interlayers, Polymer Degradation and Stability 126 (2016) 188-195. doi:10.1016/j . polymdegradstab. 2016.02.011.

URL http://dx.doi .org/10.1016/j.polymdegradstab . 2016.02.011

[34] P. Akangah, S. Lingaiah, K. Shivakumar, Effect of Nylon 6,6 nanofiber interleaving on impact damage resistance of epoxy/carbon fiber composite laminates, Composite Structures 92 (6) (2010) 1432-1439. doi:10.1016/j.compstruct.2009.11.009.

URL http://dx.doi.org/10.1016/j. compstruct.2009.11.009

[35] R. Palazzetti, Flexural behavior of carbon and glass fiber composite laminates reinforced with Nylon 6,6 electrospun nanofibers, Journal of Composite Materials 49 (27) (2015) 3407-3413. doi:10.1177/0021998314565410.

URL http://jcm. sagepub.com/cgi/doi/10.1177/0021998314565410

[36] K. Shivakumar, S. Lingaiah, H. Chen, P. Akangah, G. Swaminathan, L. Russell, Polymer Nanofabric Interleaved Composite Laminates, AIAA Journal 47 (7) (2009) 1723-1729. doi:10.2514/1.41791.

[37] T. Brugo, R. Palazzetti, The effect of thickness of Nylon 6,6 nanofibrous mat on Modes I-II fracture mechanics of UD and woven composite laminates, Composite Structures 154 (2016) 172-178. doi: 10.1016/j. compstruct.2016.07.034.

[38] L. Daelemans, S. van der Heijden, I. De Baere, H. Rahier, W. Van Paepegem, K. De Clerck, Nanofibre bridging as a toughening mechanism in carbon/epoxy composite laminates interleaved with electrospun polyamide nanofibrous veils, Composites Science and Technology 117 (2015) 244-256. doi:10.1016/j . compscitech.2015.06.021. URL http://dx.doi.org/10.1016/j.compscitech.2015.06.021

[39] T. Brugo, G. Minak, A. Zucchelli, H. Saghafi, M. Fotouhi, An Investigation on the Fatigue based Delamination of Woven Carbon-epoxy Composite Laminates Reinforced with Polyamide Nanofibers, Procedia Engineering 109 (2015) 65-72. doi:10.1016/j. proeng. 2015.06.208. URL http://linkinghub.elsevier.com/retrieve/pii/S1877705815011704 
[40] P. Akangah, K. Shivakumar, Impact damage resistance and tolerance of polymer nanofiber interleaved composite laminates, in: 53rd AIAA/ASME/ASCE/AHS/ASC Structures, Structural Dynamics and Material Conference, no. April, Honolulu, Hawaii, USA, 2012.

[41] R. Palazzetti, A. Zucchelli, C. Gualandi, M. Focarete, L. Donati, G. Minak, S. Ramakrishna, Influence of electrospun Nylon 6,6 nanofibrous mats on the interlaminar properties of Gr-epoxy composite laminates, Composite Structures 94 (2) (2012) 571-579. doi: 10.1016/j. compstruct. 2011.08.019. URL http://dx.doi.org/10.1016/j. compstruct.2011.08.019

[42] R. Palazzetti, A. Zucchelli, I. Trendafilova, The self-reinforcing effect of Nylon 6,6 nano-fibres on CFRP laminates subjected to low velocity impact, Composite Structures 106 (2013) 661-671. doi: 10.1016/j.compstruct.2013.07.021. URL http://dx.doi.org/10.1016/j. compstruct. 2013.07.021

[43] S. Hamer, H. Leibovich, A. Green, R. Intrater, R. Avrahammi, E. Zussman, A. Siegmann, D. Sherman, Mode I interlaminar fracture toughness on Nylon 66 nanofibreilmat interleaved carbon/epoxy laminates, Polymer Composites 32 (11) (2011) 1781-1789. doi:10.1002/pc.

[44] R. Palazzetti, X. Yan, A. Zucchelli, Influence of geometrical features of electrospun Nylon 6,6 interleave in the CFRP laminates mechanical properties, Polymers and Polymer Composites 35 (1) (2014) 137-150. doi:10.1002/pc.

[45] T. Brugo, G. Minak, A. Zucchelli, X. Yan, J. Belcari, H. Saghafi, R. Palazzetti, Study on Mode I fatigue behaviour of Nylon 6,6 nanoreinforced CFRP laminates, Composite Structures 164 (2017) 51-57. doi:10.1016/j. compstruct.2016.12.070.

URL http://linkinghub.elsevier.com/retrieve/pii/S0263822316320542

[46] H. Saghafi, R. Palazzetti, A. Zucchelli, G. Minak, Influence of electrospun nanofibers on the interlaminar properties of unidirectional epoxy resin/glass fiber composite laminates, Journal of Reinforced Plastics and Composites 34 (11) (2015) 907-914. 
[47] C. Garcia, J. Wilson, I. Trendafilova, L. Yang, Vibratory behaviour of glass fibre reinforced polymer (GFRP) interleaved with nylon nanofibers, Composite Structures 176 (2017) 923-932. doi:10.1016/j. compstruct.2017.06.018.

URL http://linkinghub.elsevier.com/retrieve/pii/S0263822316325454

[48] H. Saghafi, A. Zucchelli, R. Palazzetti, G. Minak, The effect of interleaved composite nanofibrous mats on delamination behavior of polymeric composite materials, Composite Structures 109 (1) (2014) 41-47. doi:10.1016/j.compstruct.2013.10.039. URL http://dx.doi.org/10.1016/j.compstruct.2013.10.039

[49] L. Daelemans, S. van der Heijden, I. De Baere, H. Rahier, W. Van Paepegem, K. De Clerck, Using aligned nanofibres for identifying the toughening micromechanisms in nanofibre interleaved laminates, Composites Science and Technology 124 (2016) 17-26. doi: 10.1016/j.compscitech.2015.11.021.

[50] S. van der Heijden, L. Daelemans, B. De Schoenmaker, I. De Baere, H. Rahier, W. Van Paepegem, K. De Clerck, Interlaminar toughening of resin transfer moulded glass fibre epoxy laminates by polycaprolactone electrospun nanofibres, Composites Science and Technology 104 (2014) 66-73. doi:10.1016/j.compscitech.2014.09.005.

URL http://dx.doi.org/10.1016/j. compscitech.2014.09.005

[51] H. Saghafi, T. Brugo, G. Minak, A. Zucchelli, Improvement the impact damage resistance of composite materials by interleaving Polycaprolactone nanofibers, Engineering Solid Mechanics 3 (1) (2015) 21-26. doi:10.5267/j.esm.2014.12.003.

URL http://www . growingscience. com/esm/Vol3/esm\{_\}2014\{_\}33.pdf

[52] J. Zhang, T. Lin, X. Wang, Electrospun nanofibre toughened carbon/epoxy composites: Effects of polyetherketone cardo (PEK-C) nanofibre diameter and interlayer thickness, Composites Science and Technology 70 (11) (2010) 1660-1666. doi: 10.1016/j. compscitech. 2010.06.019. URL http://dx.doi.org/10.1016/j.compscitech.2010.06.019

[53] K. Magniez, T. Chaffraix, B. Fox, Toughening of a carbon-fibre composite using electrospun poly(hydroxyether of bisphenol A) nanofibrous 
membranes through inverse phase separation and inter-domain etherification, Materials 4 (11) (2011) 1967-1984. doi:10.3390/ma4111967.

[54] H. Zhang, A. Bharti, Z. Li, S. Du, E. Bilotti, T. Peijs, Localized toughening of carbon / epoxy laminates using dissolvable thermoplastic interleaves and electrospun fibres, Composites Part A: Applied Science and Manufacturing 79 (2015) 116-126. doi: 10.1016/j . compositesa.2015.09.024.

URL http://dx.doi.org/10.1016/j.compositesa.2015.09.024

[55] S. Boccardi, C. Meola, G. Carlomagno, L. Sorrentino, G. Simeoli, P. Russo, Effects of interface strength gradation on impact damage mechanisms in polypropylene/woven glass fabric composites, Composites Part B: Engineering 90 (2016) 179-187. doi: 10.1016/j.compositesb.2015.12.004. URL http://dx.doi.org/10.1016/j.compositesb.2015.12.004

[56] V. Ramirez, P. Hogg, W. Sampson, The influence of the nonwoven veil architectures on interlaminar fracture toughness of interleaved composites, Composites Science and Technology 110 (2015) 103-110. doi:10.1016/j.compscitech.2015.01.016. URL http://dx.doi.org/10.1016/j.compscitech.2015.01.016

[57] G. Li, P. Li, C. Zhang, Y. Yu, H. Liu, S. Zhang, X. Jia, X. Yang, Z. Xue, S. Ryu, Inhomogeneous toughening of carbon fiber/epoxy composite using electrospun polysulfone nanofibrous membranes by in situ phase separation, Composites Science and Technology 68 (3-4) (2008) 987-994. doi:10.1016/j.compscitech.2007.07.010. URL http: //linkinghub.elsevier.com/retrieve/pii/S0266353807002886

[58] G. Li, P. Li, Y. Yu, X. Jia, S. Zhang, X. Yang, S. Ryu, Novel carbon fiber/epoxy composite toughened by electrospun polysulfone nanofibers, Materials Letters 62 (3) (2008) 511-514. doi: $10.1016 /$ j.matlet.2007.05.080.

[59] B. Beylergil, M. Tanolu, E. Akta, Modification of carbon fibre/epoxy composites by polyvinyl alcohol (PVA) based electrospun nanofibres, Advanced Composite Letters 25 (3) (2016) 69-76. 
[60] Y. Shao, T. Yashiro, K. Okubo, T. Fujii, Effect of cellulose nano fiber $(\mathrm{CNF})$ on fatigue performance of carbon fiber fabric composites, Composites Part A: Applied Science and Manufacturing 76. doi:10.1016/j.compositesa.2015.05.033.

[61] K. Magniez, C. De Lavigne, B. L. Fox, The effects of molecular weight and polymorphism on the fracture and thermo-mechanical properties of a carbon-fibre composite modified by electrospun poly (vinylidene fluoride) membranes, Polymer 51 (12) (2010) 2585-2596. doi:10.1016/j.polymer.2010.04.021. URL http://dx.doi.org/10.1016/j.polymer.2010.04.021

[62] M. Fotouhi, H. Saghafi, T. Brugo, G. Minak, C. Fragassa, A. Zucchelli, M. Ahmadi, Effect of PVDF nanofibers on the fracture behavior of composite laminates for high-speed woodworking machines, Proceedings of the Institution of Mechanical Engineers, Part C: Journal of Mechanical Engineering Science 231 (1). doi:10.1177/0954406216650711.

[63] H. Saghafi, T. Brugo, G. Minak, A. Zucchelli, The effect of PVDF nanofibers on mode-I fracture toughness of composite materials, Composites Part B: Engineering 72 (2015) 213-216. doi: 10.1016/j.compositesb.2014.12.015.

URL http://dx.doi.org/10.1016/j.compositesb.2014.12.015

[64] H. Saghafi, R. Palazzetti, A. Zucchelli, G. Minak, Impact response of glass/epoxy laminate interleaved with nanofibrous mats, Engineering Solid Mechanics 1 (2013) 85-90. doi:10.5267/j.esm.2013.09.002. URL http://www.growingscience.com/esm/Vol1/esm\{_\}2013\{_\}11.pdf

[65] H. Saghafi, S. Ghaffarian, T. Brugo, G. Minak, A. Zucchelli, H. Saghafi, The effect of nanofibrous membrane thickness on fracture behaviour of modified composite laminates - A numerical and experimental study, Composites Part B: Engineering 101 (2016) 116-123.

[66] K. Bilge, S. Venkataraman, Y. Menceloglu, M. Papila, Global and local nanofibrous interlayer toughened composites for higher in-plane strength, Composites Part A: Applied Science and Manufacturing 58 (2014) 73-76. doi:10.1016/j.compositesa.2013.12.001.

URL http://dx.doi.org/10.1016/j.compositesa.2013.12.001 
[67] E. Özden-Yenigün, K. Bilge, E. Sünbülolu, E. Bozda, M. Papila, High strain rate response of nanofiber interlayered structural composites, Composite Structures 168 (2017) 47-55. doi: 10.1016/j. compstruct. 2017.02.007.

[68] S. van der Heijden, L. Daelemans, K. De Bruycker, R. Simal, I. De Baere, W. Van Paepegem, H. Rahier, K. De Clerck, Novel composite materials with tunable delamination resistance using functionalizable electrospun SBS fibers, Composite Structures 159 (2017) 12-20. doi: 10.1016/j . compstruct. 2016.09.057. URL http://dx.doi.org/10.1016/j.compstruct.2016.09.057

[69] C. Vu, H. Choi, Enhancement of Interlaminar Fracture Toughness of Carbon Fiber/Epoxy Composites Using Silk Fibroin Electrospun Nanofibres, Polymer-Plastics Technology and Engineering 2559 (July) (2016) 03602559.2015.1132459. doi:10.1080/03602559.2015.1132459.

URL http://www . tandfonline.com/doi/full/10.1080/03602559.2015.1132459

[70] J. Monfared Zanjani, B. Okan, Y. Menceloglu, M. Yildiz, Nanoengineered design and manufacturing of high-performance epoxy matrix composites with carbon fiber/selectively integrated graphene as multi-scale reinforcements, RSC Advances 6 (12) (2016) 9495-9506. doi:10.1039/C5RA23665G. URL http://xlink.rsc.org/?DOI=C5RA23665G

[71] Y. Zhao, T. Xu, X. Ma, M. Xi, D. Salem, H. Fong, Hybrid multi-scale epoxy composites containing conventional glass microfibers and electrospun glass nanofibers with improved mechanical properties, Journal of Applied Polymer Science 132 (44). doi:10.1002/app. 42731.

URL http://doi.wiley.com/10.1002/app. 42731

[72] D. Shinde, F. White, A. Kelkar, Flexural behavior of fiberglass polymer composite with and without TEOS electrospun nanofibers, in: ASME 2014 International Mechanical Engineering Congress \& Exposition, Montreal, Quebec, Canada, 2014.

[73] A. Kelkar, R. Mohan, R. Bolick, S. Shendokar, Effect of nanoparticles and nanofibers on Mode I fracture toughness of fiber glass 
reinforced polymeric matrix composites, Materials Science and Engineering B 168 (1-3) (2010) 85-89. doi:10.1016/j.mseb . 2010.01.015. URL http://linkinghub.elsevier.com/retrieve/pii/S0921510710000218

[74] R. Mohan, E. Kimbro, Computational and Experimental Investigation of the Low Velocity Impact Behavior of Nano Engineered E-Glass Fiber, in: ASME 2012 International Mechanical Engineering Congress \& Exposition, Huston, Texas, USA, 2012.

[75] E. Kimbro, Development of Energy Absorbing Laminated Fiberglass, in: ASME 2011 International Mechanical Engineering Congress \& Exposition, Denver, Colorado, USA, 2011.

[76] E. Kimbro, A. Kelkar, R. Mohan, Compression after impact behavior of electrospun nanofiber embedded fiber glass composite laminates, in: 15th European Conference on Composite Materials, no. June, 2012, pp. 24-28.

[77] D. Shinde, A. Kelkar, Effect of TEOS Electrospun Nanofiber Modified Resin on Interlaminar Shear Strength of Glass Fiber / Epoxy Composite, International Journal of Chemical, Molecular, Nuclear, Materials and <etallurgical Engineering 8 (1) (2014) 54-60.

[78] D. Shinde, A. Kelkar, Short beam strenght of laminated fiberglass composites with and without electrospub TEOS nanofibers, in: SAMPE Conference Proceedings, no. June, 2016.

[79] K. Shivakumar, R. Panduranga, Interleaved polymer matrix composites - A review, Collection of Technical Papers AIAA/ASME/ASCE/AHS/ASC Structures, Structural Dynamics and Materials Conference (2013) 1-13doi:10.2514/6.2013-1903.

URL http://www.scopus.com/inward/record.url?eid= 2-s2.0-84881364474\{\&\}partnerID=tZOtx3y1

[80] S. Sihn, R. Kim, W. Huh, K. Lee, A. Roy, Improvement of damage resistance in laminated composites with electrospun nanointerlayers, Composites Science and Technology 68 (2008) 673-683. doi:10.1016/j.compscitech.2007.09.015. 
[81] M. Kiasat, R. Najarian, Carbon nanofiber hybrid laminates fabrication and characterization, in: 18th International Conference on Composite Materials, 2011.

[82] S. Sinha-Ray, D. Pelot, Z. Zhou, A. Rahman, X. Wu, A. Yarin, Encapsulation of self-healing materials by coelectrospinning, emulsion electrospinning, solution blowing and intercalation, Journal of Materials Chemistry 22 (18) (2012) 9138-9146. doi:10.1039/c2jm15696b.

[83] M. Arai, T. Sasaki, S. Hirota, H. Ito, N. Hu, M. Quaresimin, Mixed modes interlaminar fracture toughness of CFRP laminates toughened with CNF interlayer, Acta Mechanica Solida Sinica 25 (3) (2012) 321-330. doi:10.1016/S0894-9166(12)60029-9.

URL http://linkinghub.elsevier.com/retrieve/pii/S0894916612600299

[84] S. Dhakate, A. Chaudhary, A. Gupta, A. Pathak, B. Singh, K. Subhedar, T. Yokozeki, Excellent mechanical properties of carbon fiber semi-aligned electrospun carbon nanofiber hybrid polymer composites, RSC Advances 6 (43) (2016) 36715-36722. doi:10.1039/C6RA02672A. URL http://pubs.rsc.org/en/content/articlehtml/2016/ra/c6ra02672a

[85] I. Guseva Canu, T. Bateson, V. Bouvard, M. Debia, C. Dion, K. Savolainen, I. Yu, Human exposure to carbon-based fibrous nanomaterials: A review, International Journal of Hygiene and Environmental Health 219 (2) (2016) 166-175. doi:10.1016/j.ijheh.2015.12.005.

[86] J. Park, J. Jang, Z. Wang, D. Kwon, K. Devries, Self-sensing of carbon fiber/carbon nanofiber-epoxy composites with two different nanofiber aspect ratios investigated by electrical resistance and wettability measurements, Composites Part A: Applied Science and Manufacturing 41 (11) (2010) 1702-1711. doi: 10.1016/j. compositesa. 2010.08.005.

[87] S. Jiang, G. Duan, J. Schöbel, S. Agarwal, A. Greiner, Short electrospun polymeric nanofibers reinforced polyimide nanocomposites, Composites Science and Technology 88 (2013) 57-61. doi: 10.1016/j. compscitech. 2013.08.031. URL http://dx.doi.org/10.1016/j.compscitech.2013.08.031 
[88] S. Van Der Heijden, B. De Schoenmaker, H. Rahier, G. Van Assche, K. De Clerck, The effect of the moisture content on the curing characteristics of an epoxy matrix in the presence of nanofibrous structures, Polymer Testing 40 (2014) 265-272. doi:10.1016/j.polymertesting.2014.08.019.

URL http://dx.doi .org/10.1016/j.polymertesting. 2014.08.019

[89] B. De Schoenmaker, S. van der Heijden, S. Moorkens, H. Rahier, G. van Assche, K. De Clerck, Effect of nanofibres on the curing characteristics of an epoxy matrix, Composites Science and Technology 79 (2013) 3541. doi:10.1016/j.compscitech.2013.02.009.

URL http://dx.doi.org/10.1016/j.compscitech.2013.02.009

[90] J. Kim, D. Reneker, Mechanical properties of composites using ultrafine electrospun fibers, Polymer Composites 20 (1) (1999) 124-131. doi:10.1002/pc.10340.

URL http://doi.wiley.com/10.1002/pc.10340http: //www. scopus.com/inward/record.url?eid= 2-s2.0-0033077639 $\{\&\}$ partner ID $=40\{\&\} \mathrm{md5}=$ 27c15385b1d37abd597b1d312fc083d5

[91] Y. Dong, T. Mosaval, H. Haroosh, A novel epoxy/electrospun PLA nanofibre composite material: fabrication and characterisation, in: Fourth International Conference on Smart Materials and Nanotechnology in Engineering, Vol. 8793, Gold Coast, Australia, 2013. doi: $10.1117 / 12.2025370$.

[92] S. Lin, Q. Cai, J. Ji, G. Sui, Y. Yu, X. Yang, Q. Ma, Y. Wei, X. Deng, Electrospun nanofiber reinforced and toughened composites through in situ nano-interface formation, Composites Science and Technology 68 (15-16) (2008) 3322-3329. doi: 10.1016/j.compscitech.2008.08.033.

URL http://dx.doi.org/10.1016/j.compscitech.2008.08.033

[93] S. Alessi, M. di Filippo, C. Dispenza, M. Focarete, C. Gualandi, R. Palazzetti, G. Pitarresi, A. Zucchelli, Effects of Nylon 6,6 Nanofibrous Mats on Thermal Properties and Delamination Behavior of High Performance CFRP Laminates, Polymer Composites 36 (7) (2015) 1303-1313. doi:10.1002/pc. 
[94] S. Karimi, M. Staiger, N. Buunk, A. Fessard, N. Tucker, Uniaxially aligned electrospun fibers for advanced nanocomposites based on a model PVOH-epoxy system, Composites Part A: Applied Science and Manufacturing 81 (2016) 214-221. doi: 10.1016/j. compositesa.2015.11.016.

URL http://dx.doi.org/10.1016/j.compositesa.2015.11.016

[95] S. Mohammadzadehmoghadam, Y. Dong, I. Jeffery Davies, Recent progress in electrospun nanofibers: Reinforcement effect and mechanical performance, Journal of Polymer Science, Part B: Polymer Physics 53 (17) (2015) 1171-1212. doi:10.1002/polb. 23762.

[96] A. Baji, Y. Mai, S. Wong, M. Abtahi, P. Chen, Electrospinning of polymer nanofibers: Effects on oriented morphology, structures and tensile properties, Composites Science and Technology 70 (5) (2010) 703-718. doi:10.1016/j. compscitech.2010.01.010. URL http://dx.doi.org/10.1016/j.compscitech.2010.01.010

[97] S. Lingaiah, K. Shivakumar, R. Sadler, Electrospinning of Nylon-66 Polymer Nanofabrics, in: 49th AIAA/ASME/ASCEAHS/ASC Structures, Structural Dynamics and Materials Conference, 2008, pp. 1-13.

[98] S. Jiang, G. Duan, E. Zussman, A. Greiner, S. Agarwal, Highly Flexible and Tough Concentric Triaxial Polystyrene Fibers, ACS Applied Materials \& Interfaces 6 (8) (2014) 5918-5923. doi:10.1021/am500837s. URL http://pubs.acs.org/doi/abs/10.1021/am500837s

[99] A. Rasel, Computational modeling of low velocity impact loading of composite with and without electrospun nanofibers, Ph.D. thesis, North Carolina A\&T State University (2011).

[100] F. Moroni, R. Palazzetti, A. Zucchelli, A. Pirondi, A numerical investigation on the interlaminar strength of nanomodified composite interfaces, Composites Part B: Engineering 55 (2013) 635-641. doi: 10.1016/j. compositesb. 2013.07.004.

URL http://dx.doi.org/10.1016/j.compositesb.2013.07.004

[101] G. Giuliese, R. Palazzetti, F. Moroni, A. Zucchelli, A. Pirondi, Cohesive zone modelling of delamination response of a composite laminate with interleaved Nylon 6,6 nanofibres, Composites Part B: Engineering 78 
(2015) 384-392. doi:10.1016/j. compositesb.2015.03.087.

URL http://dx.doi.org/10.1016/j.compositesb.2015.03.087

[102] H. Saghafi, S. Ghaffarian, D. Salimi-Majd, H. Saghafi, Investigation of interleaf sequence effects on impact delamination of Nano-modified woven composite laminates using cohesive zone model, Composite Structures 166 (2017) 49-56. doi:10.1016/j.compstruct.2017.01.035. URL http://linkinghub.elsevier.com/retrieve/pii/S026382231631786X

[103] J. Yao, C. Bastiaansen, T. Peijs, High Strength and High Modulus Electrospun Nanofibers, Fibers 2 (2014) 158-187. doi: 10.3390/fib2020158.

[104] N. Fallahi, G. Nardoni, H. Heidary, R. Palazzetti, X. Yan, A. Zucchelli, Supervised and Non-supervised AE Data Classification of Nanomodified CFRP During DCB Tests, FME Transaction 44 (4) (2016) 415-421. doi:10.5937/fmet1604415F.

[105] F. Wang, Y. Mai, D. Wang, R. Ding, W. Shi, High quality barium titanate nanofibers for flexible piezoelectric device applications, Sensors and Actuators, A: Physical 233 (2015) 195-201. doi: 10.1016/j.sna.2015.07.002.

URL http://dx.doi.org/10.1016/j.sna.2015.07.002

[106] K. Friedrich, Applications of Fracture Mechanics to Composite Materials, Elsevier Science Publishers, 1989.

[107] P. Davies, B. Blackman, A. Brunner, Standard Test Methods for Delamination Resistance of Composite Materials: Current Status, Applied Composite Materials 5 (1998) 345-364.

[108] ASTM D5528-13, Standard Test Method for Mode I Interlaminar Fracture Toughness of Unidirectional Fiber-Reinforced Polymer Matrix Composites, Annual Book of ASTM Standards (2014) 113doi:10.1520/D5528-13.2.

URL http://scholar.google.com/scholar?hl=en $\{\&\}$ btnG= Search $\{\&\} q=$ intitle: Standard+Test+Method+for+Mode+I+ Interlaminar+Fracture+Toughness+of+Unidirectional+ Fiber-Reinforced+Polymer+Matrix+Composites $\{\#\} 2$ 
[109] C. Brinker, G. Scherer, Sol-Gel Science. The physics and chemistry of Sol-Gel Science, 1990. doi:10.1016/B978-0-08-057103-4.50001-5.

[110] I. Martinez, M. Martin, A. Eceiza, P. Oyanguren, I. Mondragon, Phase separation in polysulfone-modified epoxy mixtures. Relationships between curing conditions, morphology and ultimate behavior, Polymer 41 (3) (2000) 1027-1035. doi:10.1016/S0032-3861 (99) 00238-4.

[111] ASTM D7905/D7905M-14, Standard Test Method for Determination of the Mode II Interlaminar Fracture Toughness of Unidirectional Fiber-Reinforced Polymer Matrix Composites, Annual Book of ASTM Standardsdoi: 10.1520/D7905.

[112] European Structural Integrity Society, Protocol No 2 for interlaminar fracture toughness testing of composites: Mode II, Bordeaux, 1993.

[113] W. Chan, O. Ochoa, Edge delamination resistance by a crictical ply termination, Key Engineering Materials 37 (1989) 285-304. doi: 10.4028/www. scientific.net/KEM.37.285. URL http://www.scientific.net/KEM.37.285

[114] S. Abrate, Impact on Composite Structures, Cambridge University Press, 2005.

[115] I. Trendafilova, R. Palazzetti, A. Zucchelli, Delamination Assessment in Structures Made of Composites Based on General Signal Correlation, International Journal of Structural Stability and Dynamics 14 (8) (2014) 1440022. doi:10.1142/S0219455414400227. URL http://www . worldscientific. com/doi/abs/10.1142/S0219455414400227

[116] I. Trendafilova, R. Palazzetti, A. Zucchelli, Damage assessment based on general signal correlation. Application for delamination diagnosis in composite structures, European Journal of Mechanics - A/Solids 49 (2015) 197-204. doi:10.1016/j .euromechsol.2014.07.007. URL http://linkinghub.elsevier.com/retrieve/pii/S099775381400103X

[117] D. Garcia, R. Palazzetti, I. Trendafilova, C. Fiorini, a. Zucchelli, Vibration-based delamination diagnosis and modelling for composite laminate plates, Composite Structures 130 (2015) 155-162. doi:10.1016/j.compstruct.2015.04.021. URL http://linkinghub.elsevier.com/retrieve/pii/S0263822315003165 
[118] S. Arshad, M. Naraghi, I. Chasiotis, Strong carbon nanofibers from electrospun polyacrylonitrile, Carbon 49 (5) (2011) 1710-1719. doi: 10.1016/j.carbon.2010.12.056.

URL http://dx.doi.org/10.1016/j. carbon.2010.12.056

[119] L. Hu, D. Hecht, G. Gru, Carbon Nanotube Thin Films: Fabrication , Properties , and Applications, Chemical Review 110 (10) (2010) 57905844.

[120] E. Hammel, X. Tang, M. Trampert, T. Schmitt, K. Mauthner, A. Eder, P. Pötschke, Carbon nanofibers for composite applications, Carbon 42 (5-6) (2004) 1153-1158. doi:10.1016/j . carbon.2003.12.043.

[121] K. Bilge, E. Ozden-Yenigun, E. Simsek, Y. Menceloglu, M. Papila, Structural composites hybridized with epoxy compatible polymer/MWCNT nanofibrous interlayers, Composites Science and Technology 72 (14) (2012) 1639-1645. doi:10.1016/j.compscitech.2012.07.005. URL http://dx.doi.org/10.1016/j.compscitech.2012.07.005

[122] I. Subagia, L. Tijing, Y. Kim, Basalt Fabric-Electrospun Nanofiber-Based Composite Laminates, Applied Mechanics and Materials 465-466 (2014) 852-856. doi: 10.4028/www. scientific.net/AMM. 465-466.852.

[123] I. Subagia, Z. Jiang, L. Tijing, Y. Kim, C. Kim, J. Lim, H. Shon, Hybrid multi-scale basalt fiber-epoxy composite laminate reinforced with electrospun polyurethane nanofibers containing carbon nanotubes, Fibers and Polymers 15 (6) (2014) 1295-1302. doi: 10.1007/s12221-014-1295-4.

[124] G. Liao, Q. You, H. Xia, D. Wang, Preparation and properties of novel epoxy composites containing electrospun PA6/F-MWNTs fibers, Polymer Engineering and Science 56 (2016) 1259-1266. arXiv:0406218, doi:10.1002/pen.

URL http://doi.wiley.com/10.1002/pen. 20921

[125] N. Zheng, Y. Huang, H. Liu, J. Gao, Y. Mai, Improvement of interlaminar fracture toughness in carbon fiber/epoxy composites with carbon 
nanotubes/polysulfone interleaves, Composites Science and Technology 140 (2017) 8-15. doi:10.1016/j. compscitech.2016.12.017. URL http://linkinghub.elsevier.com/retrieve/pii/S0266353816306765

[126] T. Baier, G. Dupeux, S. Herbert, S. Hardt, D. Quere, Propulsion Mechanisms for Leidenfrost Solids on Ratchets (aug 2012). arXiv:1208.5721, doi:10.1103/PhysRevE. 87.021001. URL http://arxiv.org/abs/1208.5721http: //dx.doi.org/10.1103/PhysRevE.87.021001 